Portland State University

PDXScholar

6-2-1997

\title{
Predictions of Intentions of College Students to Take an HIV Antibody Test and Their Preferences for a Testing Procedure
}

Hitoshi Ishimaru

Portland State University

Follow this and additional works at: https://pdxscholar.library.pdx.edu/open_access_etds

Part of the Psychology Commons

Let us know how access to this document benefits you.

Recommended Citation

Ishimaru, Hitoshi, "Predictions of Intentions of College Students to Take an HIV Antibody Test and Their Preferences for a Testing Procedure" (1997). Dissertations and Theses. Paper 5349.

https://doi.org/10.15760/etd.7222

This Thesis is brought to you for free and open access. It has been accepted for inclusion in Dissertations and Theses by an authorized administrator of PDXScholar. Please contact us if we can make this document more accessible: pdxscholar@pdx.edu. 


\section{THESIS APPROVAL}

The abstract and thesis of Hitoshi Ishimaru for the Master of Science in Psychology were presented June 2, 1997, and accepted by the thesis committee and the department.

COMMITTEE APPROVALS:

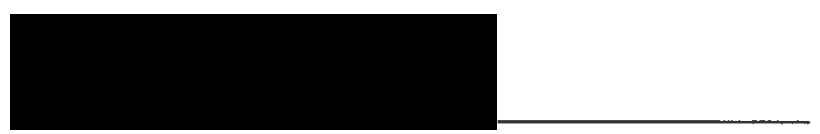

Laurie Skokan, Chair
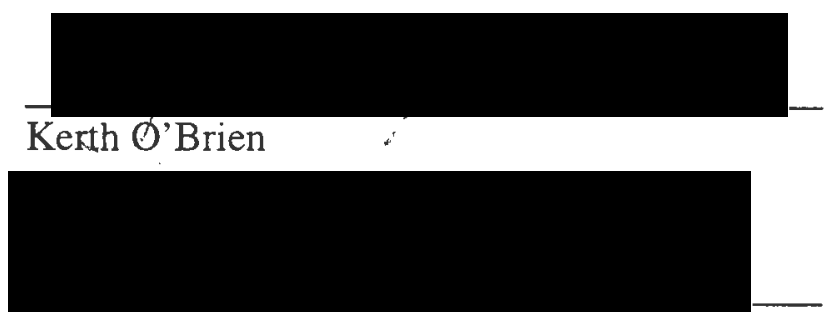

Valerie Dull

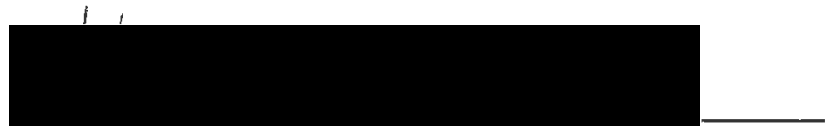

Sherril Gelmon

Representative of the Office of Graduate Studies

DEPARTMENT APPROVAL:

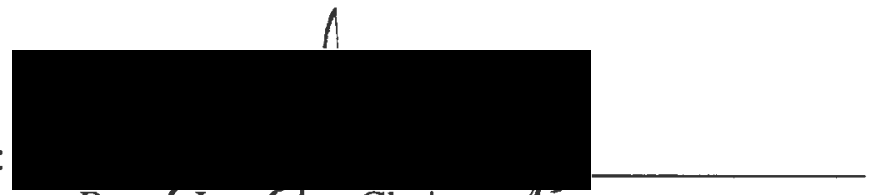

Roger Jenrings, Chair

Department of Psychologly

$* * * * * * * * * * * * * * * * * * * * * * * * * * * * * * * * * * * * * * * * * * * * * * * * * * * * * * * * * * * * * * * * * * * *$

ACCEPTED FOR PORTLAND STATE UNIVERSITY BY THE LIBRARY

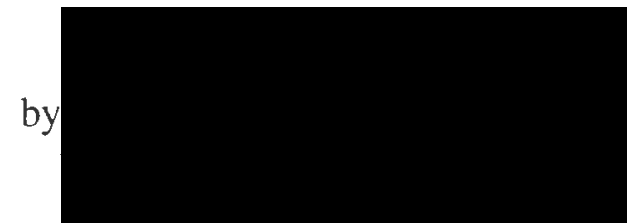

on

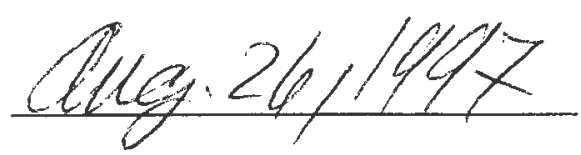




\begin{abstract}
An abstract of the thesis of Hitoshi Ishimaru for the Master of Science in Psychology presented June 2, 1997.
\end{abstract}

Title: Predictions of Intentions of College Students to Take an HIV Antibody Test and Their Preferences for a Testing Procedure.

Intentions to prevent HIV infections are an essential part of HIV prevention. Social science researchers and HIV educators have investigated the roles of intentions to prevent HIV infections mainly in the context of safer sex behaviors. Surprisingly, however, HIV testing intentions have not been extensively studied in light of various forms of HIV tests that are likely soon to be approved for widespread use.

The present study evaluated the utility of Ajzen and Fishbein's (1980) Theory of Reasoned Action in predicting college students' intentions to take an HIV test. Attitudes toward HIV testing and their perceptions of social pressure toward HIV tests were investigated as predictors of testing intentions. In addition, college students' preferences for HIV testing procedures were surveyed in order to investigate whether the characteristics of the new HIV tests were seen as favorable. 
Responses from 190 undergraduate and graduate students at Portland State University (Portland, Oregon) were analyzed by multiple linear regression analysis. Results strongly supported the impact of the subjective norm toward HIV testing as a determinant of testing intentions. On the other hand, testing attitudes failed to predict testing intentions unlike past studies on HIV preventive behavioral intentions. Regarding the procedural preferences, the majority of respondents preferred the procedures of conventional HIV tests except that most respondents preferred not to have post-test counseling after an HIV-negative result: in addition, respondents were equally divided in their preference for blood or saliva fluid sampling.

Implications of these findings are discussed for possible interventions. 
PREDICTIONS OF INTENTIONS OF COLLEGE STUDENTS

TO TAKE AN HIV ANTIBODY TEST AND THEIR

PREFERENCES FOR A TESTING PROCEDURE

by

HITOSHI ISHIMARU

A thesis submitted in partial fulfillment of the requirements for the degree of

MASTER OF SCIENCE

in

PSYCHOLOGY

Portland State University

1997 


\section{ACKNOWLEDGMENTS}

I would like to thank several people for assisting me with this thesis and giving me the support that I value most.

- Committee chair, Dr. Laurie Skokan, for assisting me through the course of the program and especially for being very patient for endless revisions of this thesis.

- Dr. Kerth $\mathrm{O}^{\prime}$ Brien, for providing me the in-depth thoughts of issues on HIV and AIDS.

- Dr. Valerie Dull, for introducing me to the realm of health psychology. My interest on health issues developed from an influence from her.

- Dr. Sherril Gelmon, the graduate representative, for accommodating her time so that I could have the thesis defense.

- Mr. Alan Rose and Mr. David Christensen, Cascade AIDS Project (CAP), for providing me the knowledge of HIV and AIDS. I could not have done without the inputs from them.

- Everyone whom I met in the HIV testing program at CAP, for sharing knowledge and emotions. I wish them all the best. 
TABLE OF CONTENTS

PAGE

ACKNOWLEDGMENTS

LIST OF TABLES . . . . . . . . . . . . . . . . iii

LIST OF FIGURES . . . . . . . . . . . . . . . . . . . iv

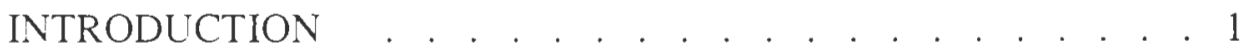

Theory of Reasoned Action . . . . . . . . . . . . . . 8

Present Study . . . . . . . . . . . . . . . . . . . . . . . . 29

METHOD .................. . . . 35

Participants . . . . . . . . . . . . . . . . . . . . 35

Measures . . . . . . . . . . . . . . . . . . . . 36

Procedure . . . . . . . . . . . . . . . . . . 39

RESLLTS . . . . . . . . . . . . . 41

DISCUSSION . . . . . . . . . . . . . . . . . . . . 60

REFERENCES . . . . . . . . . . . . . . . 78

APPENDIX (Questionnaire). . . . . . . . . . . . . . 87 


\section{LIST OF TABLES}

TABLE

PAGE

1. Percentage of Adults Who Have Already Tested . . . . . 21

2. Means and Standard Deviations of Variables in the TRA . . 43

3. Intercorrelations Among the TRA Variables . . . . . . . . 44

4. Simultaneous Multiple Linear Regression Analysis . . . . . 46

5. Contexts of Attitude as Predictors of Attitude and

Referents as Predictors of Subjective Norm . . . . . . . 49

6. Means and Standard Deviations of Perceived Risk and Concern About HIV and AIDS . . . . . . . . . . . 50

7. Pearson's Correlations of Perceived Risk and Concern

Variables with Other Variables . . . . . . . . . 52

8. Means and Standard Deviations of the TRA Variables

(with respect to relationship status) . . . . . . . . . 54

9. Percentages of Preference Selection . . . . . . . . . . . 56

10. T-Scores Between General Intentions to Take an HIV

Test and Intentions to Take a Test with Preferred

Methodological Conditions . . . . . . . . . . . . . 59 


\section{LIST OF FIGURES}

FIGURE

PAGE

1. The Theory of Reasoned Action _. . . . . . . . 10

2. The Present Study: Use of the Theory of Reasoned Action . . 12

3. Summary of Contexts of the Variables for the Questionnaire. . 30 
Predictions of Intentions of College Students to Take an HIV Antibody Test and Their Preferences for a Testing Procedure

Acquired Immune Deficiency Syndrome (AIDS) has been a devastating epidemic worldwide. Since the start of national attention to the pandemic, the prevalence of the Human Immunodeficiency Virus (HIV), which is the cause of AIDS. has been feared by many people worldwide. Although almost two decades have passed. it appears that no vaccine or cure for the HIV will be available in the immediate future. Therefore, prevention has been the major focus of AIDS education. However, the Centers for Disease Control and Prevention (CDC) have now added a new focus, shifting the priority, at least for the moment. to issues surrounding HIV antibody testing (Bayer, Stryker \& Smith. 1995: Marwick, 1995 ).

AIDS and HIV are certainly a human tragedy on a global scale. The World Health Organization (WHO) reported more than 850,000 AIDS cases, and that more than 12 million adults and more than one million children had been infected with HIV by the end of 1993 (Gale Research Inc., 1995). The WHO also estimated that by the year 2000 there will be 25 to 30 million cumulative cases of adult HIV infection in the world, with eight to ten million AIDS cases, and five to ten million cases of HIV infection in children, with four to eight million AIDS cases (Merson. 1992). As of 1995, the number of AIDS cases in the United States exceeded 500.000 and the estimated number of HIV infected people reached one million (C.S. Bureau of the Census, 1995). 
Much research attention has been given to so called "high rish groups." which typically represent homosexual and bisexual males, and injection drug users. However, the risk of contracting HIV has risen for other population groups, for example, heterosexual males and females. Some researchers report that the transmission rates through heterosexual contact have been drastically increasing (Holmes. Karon. \& Kreiss. 1990: Quin. Narain, \& Zacarias, 1990). Although the AIDS cases reported among gay and bisexual men have declined (Kelly. Kalichman \& Kauth, 1991), infection rates in women are increasing (Kalichman. Hunter. \& Kelly. 1992). The Centers for Disease Control and Prevention (CDC) (1995) reported that women constituted approximately $18 \%$ of all reported AIDS cases. Chu and his colleagues (1990) reported that AIDS was one of the top ten causes of death among women of reproductive age. Adolescents and college students were also reported to be at risk for HIV infection regardless of their sexual orientations (Petosa \& Wessinger. 1990; Leukefeld \& Haverkos, 1993: Morrison. Baker. \& Gillmore, 1994). Chilman (1983) explained the possible reasons that adolescents and college students were at risk: (1) they have a tendency to believe that they are not personally at risk: (2) they are susceptible to the influence of peer pressure: (3) they are open to sexual experimentation; and (4) they are more likely to have multiple sexual partners. Therefore, HIV and AIDS have become a nightmare not only for the groups previously identified as high risk. 
Increasing people's knowledge about HIV and AIDS has been an important goal for the prevention of HIV infections. A number of studies have focused on the knowledge level of adolescents and college students. Studies conducted in the early $1980^{\circ}$ s tended to report low knowledge levels of HIV and AIDS in adolescents and college students (Price, Desmond, \& Kukulka, 1985). Fortunately, studies in the late 1980's and 1990's reported higher levels of knowledge in the population of the same age (Manning. Barenberg. Gallese, \& Rice, 1989:

Morrison, Baker, \& Gillmore. 1994; Krahe \& Reiss, 1995). The educational efforts in schools appear to have been somewhat effective in changing knowledge levels.

Despite the increased knowledge and concern about HIV and AIDS, no drastic change in the sexual behaviors of students, nor in their sense of vulnerability to HIV has been produced. Most of the past research seems to indicate that people in general have low personal perceptions of risk to HIV. Low perception of risk was reported in high school students (Price et al., 1985); innercity pregnant women (Hobfoll et al., 1993); and adolescents (Basch. 1989; Petosa \& Wessinger. 1990: Thurman \& Franklin, 1990; Strunin. 1991). Bruce, Pilgrim. and Spivey (1994) reported that low risk perception of college students did not change after HIV education and a celebrity's HIV positive announcement. Despite higher levels of knowledge of HIV and AIDS, very low numbers of people have been tested for HIV. Freundlich and Hamilton (1996) reported a CDC study in 
1994 that showed only $18 \%$ of adults had been tested for HIV. In order to find more people with HIV. to give them the medical support they need as early as possible in the disease progression, and to prevent the transmission to other people. it is necessary to increase the number of people who go through HIV testing.

It has been estimated that more than half a million people carry HIV and do not know about it (Marwick. 1995). The reasons that many individuals do not take the HIV tests may be relatively simple. First, people do not perceive a personal risk for HIV. Second, people in general tend to wait until a symptom of any disease or illness appears before taking a screening test (Snyder, 1989). Unfortunately in this regard, HIV symptoms do not appear for a long time even when the virus is inside of the body. The CDC has reported that about a third of the people infected with HIV were not tested until they were within two months of receiving a diagnosis of AIDS, and about half were not tested until they were within a year of diagnosis (Bayer et al., 1995). Finally, people simply resist taking HIV tests. It is understandable that people do not want to know their health status for a life threatening infection. The process of taking HIV tests may also become a barrier. For example, visiting an HIV testing clinic is often a stressful experience for some people, requiring a firm decision to take a test. Embarrassment in disclosing private sexual practices is often a factor that stops people from going to a testing clinic. In addition. some people have a fear of needles which are 
necessary for taking blood in conventional HIV testing. Even worse, many people. especially those in high risk groups such as African-American and Hispanics, are not aware of HIV tests and where to go for the test (Selik, Castro, \& Pappaioanou, 1988). To combat these problems, new HIV tests were produced and approved by the Food and Drug Administration (FDA) for use. Some tests use saliva samples instead of blood and can be taken at home instead of visiting a testing clinic.

The present study has two aims. The first is to investigate the extent to which the Theory of Reasoned Action (Fishbein \& Ajzen. 1975; Ajzen \& Fishbein, 1977, 1980) is supported as a model for predicting intentions to have an HIV test among college students. The second is to examine whether college students favor the new HIV testing methods over the conventional HIV testing methods by asking about their preferences with respect to various aspects of HIV testing. Their intentions to take HIV tests that incorporate their preferences will be compared to their general intentions to take HIV tests.

\section{Theories of Health Behaviors}

Researchers. in the last two decades, have been concerned with identifying the factors that influence people's willingness to engage in health care behaviors. Among the most widely acknowledged theories in health behavior studies are Social Learning Theory (Bandura, 1977a), the Health Belief Model (Janz \& Becker, 1984), and the Theory of Reasoned Action (TRA) (Fishbein \& Ajzen, 1975). They differ in some aspects such as the theoretical objectives, antecedents. 
and processes that lead to behaviors in various circumstances.

In Social Learning Theory, human behavior is explained in terms of a triadic. dynamic, and reciprocal model in which behavior, personal factors, and environmental influences all interact. Human behavior is assumed to be influenced by learning and reinforcements in an individual's environment (Bandura, 1977a). Some elements of this theory have been incorporated into other theories. The construct of self-efficacy introduced by Bandura (1977b) has been particularly influential to today's researchers in health-related fields. However, Social Learning Theory does not specifically explain the role of intentions to engage in a particular behavior.

The Health Belief Model examines the decisions that individuals make about volitional behaviors that affect their health status. It attempts to predict behavior from a set of four variables (perceived severity, susceptibility. benefits, and barriers). Researchers have applied this theory to diverse illnesses and preventive health behaviors including HIV preventive behaviors. As in Social Learning Theory, the self-efficacy component is added to improve predictability. However, it has been criticized that not all the variables statistically contribute to predictions of behaviors. In addition, it is criticized for lacking an explanation of the relationship between attitudes and intentions.

The main focus of the present study lies in exploring the attitudinal and social contributions to HIV screening intentions. Taking the research interest into 
account, the TRA has the relevant constructs to investigate the relationships between attitudes and intentions, and therefore will be used to examine intentions to take HIV test. 
Theory of Reasoned Action

The TRA was introduced by Fishbein in 1967 to explain the role of intentions to perform a certain behavior. Since then, it has been refined and developed extensively to explain virtually any behavior over which an individual has volitional control. It has resulted in a clear set of guidelines of variable operationalization and statistical analyses introduced by Fishbein and Ajzen (1975: Ajzen \& Fishbein, 1980). Basing studies on their guidelines, many researchers have reported success in a large domain of studies including studies of health behaviors, such as prediction of testicular self-examination behaviors (Steffen. 1990), prediction of intentions to exercise and actual exercise (Theodorakis, 1994). prediction of intentions to do breast self-examination and performance of the examination (Lierman, Young. Kasprzyk. \& Benoliel, 1990). and prediction of influenza vaccination behaviors (Montano, 1986).

According to the TRA (Fishbein \& Ajzen, 1975: Ajzen \& Fishbein. 1980). the immediate determinant of a behavior is the person's intention to perform the behavior. Behavioral intentions are influenced by two conceptually distinguishable components: (a) attitude toward the behavior (positive or negative predisposition towards a specific behavior) and (b) subjective norms (perception of social pressure on the person to perform the behavior).

Two important assumptions of the TRA are that the behavior in question is under volitional control, that is. habitual and automatic behaviors are not within 
Intention to take HIV tests 9

the scope of the theory. and that the attitudinal and normative variables are based on people's beliefs toward the behaviors. Fishbein and Ajzen (1975: Ajzen \& Fishbein. 1980) specifically emphasized the use of salient beliefs in the model. Salient beliefs are beliefs that are most influential for a person at a given moment. The researchers demonstrated the effectiveness of salient beliefs by providing the past research findings on attention span and information processing which showed that only a small number of beliefs served as determinants of a person's attitude (Woodworth \& Schlosberg. 1954; Miller, 1956; Mandler. 1967).

The model further proposes that people's attitudes toward a behavior are a function of their beliefs evaluating the consequences of performing a behavior (outcome evaluation), weighted by their belief that the behavior would induce the consequences (behavioral belief). Similarly, the subjective norm is proposed to be a function of an individual's perception of the pressure from others to perform the behavior (normative beliefs). weighted by the individual's motivation to comply with these others (motivation to comply). These relationships are shown in Figure 1. At the initial level, behavior is assumed to be determined by intention. At the next level these intentions are determined in terms of attitudes and subjective norms toward the behavior. The third level accounts for attitudes and subjective norms in terms of beliefs about the consequences of performing the behavior and about the perceived expectations of relevant referents. Generally speaking, it is assumed that people intend to perform a behavior when they evaluate it positively 


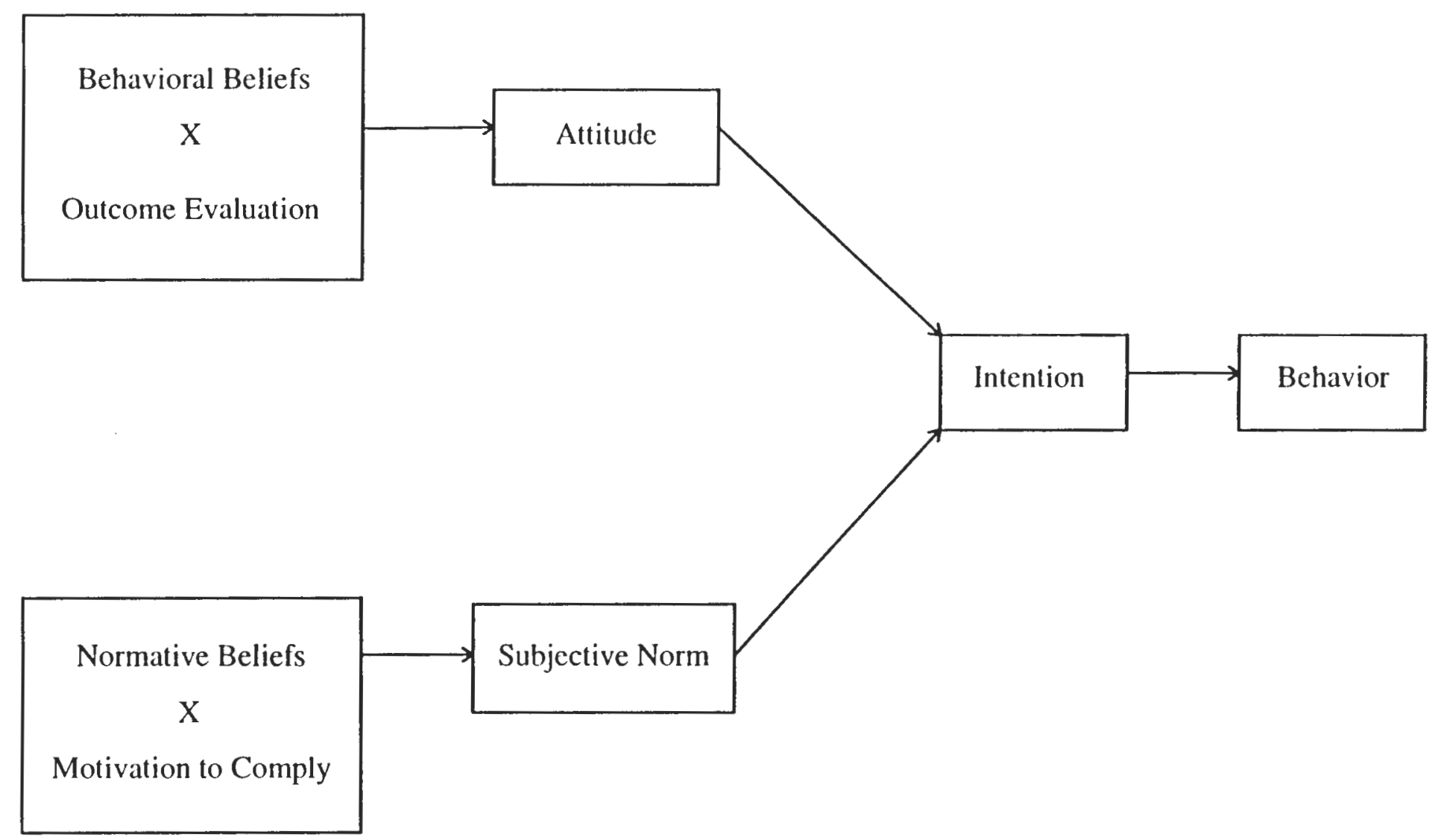

Figure 1. The Theory of Reasoned Action (Ajzen \& Fishbein, 1980). 
Intention to take HIV tests 11

and when they believe that important others think that they should perform it.

The TRA assumes that the relative importance of attitudes and subjective norms depends in part on the intention, the behavior, and the situation under investigation (Fishbein \& Ajzen, 1975). For some behaviors, subjective norms are more important in determining behavioral intentions than are attitudinal considerations. For other behaviors, the reverse may be true. For example. attitudinal considerations were found to be more important for competitive behaviors than for cooperative behaviors while subjective norms were more important for cooperation than for competitive actions (Ajzen \& Fishbein, 1980). Ajzen and Fishbein also reported that the intentions to buy some products over others were predicted more by subjective norm than attitudinal considerations. Therefore, the attitude and subjective norm components are given weights reflecting their relative importance.

\section{$\underline{\text { Attitude }}$}

Attitude is operationally defined by Ajzen and Fishbein (1980) as a person's evaluation of the target behavior or favorability toward performing the behavior. As shown in Figure 2, attitude is predicted from two factors: behavioral beliefs and outcome evaluations. Ajzen and Fishbein operationally defined behavioral beliefs as the person`s subjective judgment of the likelihood that a particular outcome will be a consequence of performing a behavior, and defined outcome evaluation as subjects' evaluations of each of the salient outcomes. The 


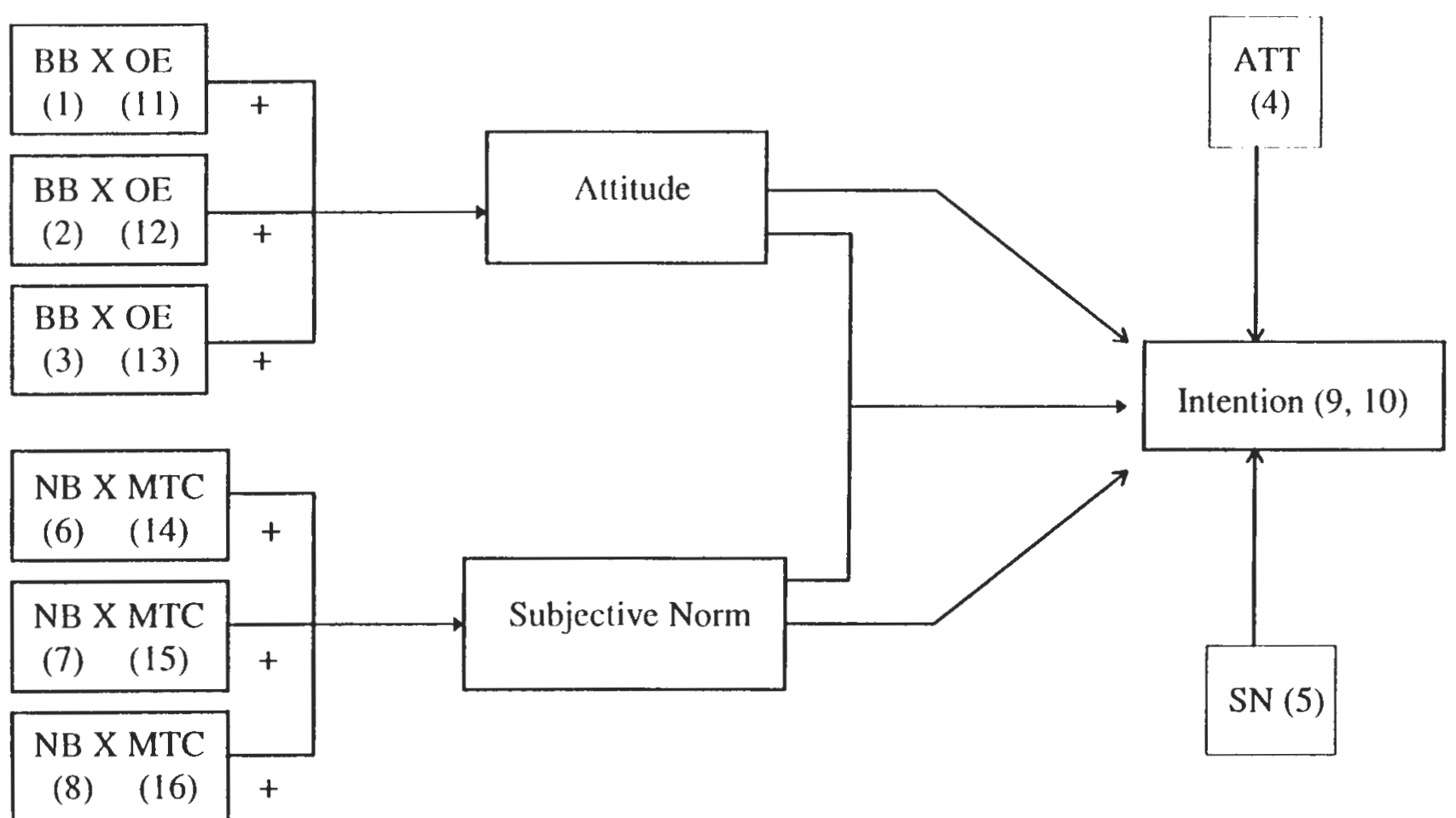

Figure 2. The Present Study: Use of the Theory of Reasoned Action.

$\mathrm{BB}=$ Behavioral Belief. $\mathrm{OE}=$ Outcome Evaluation. $\mathrm{NB}=$ Normative Belief. $\mathrm{MTC}=$ Motivation to Comply.

ATT $=$ Altitude measure from a direct question. $\mathrm{SN}=$ Subjective Norm measure from a direct question.

Inside parentheses are the question numbers used in the questionnaire. 
determination of attitude can be shown as:

$$
A_{h}=\sum_{i=1}^{n} B_{i} e_{i}
$$

$A_{b}$ : attitude toward a behavior $b$

$\mathrm{B}_{\mathrm{i}}$ : belief that performing a behavior b leads to outcome $\mathrm{i}$

$e_{i}$ : evaluation of outcome $i$

$\mathrm{n}$ : number of beliefs the person holds about performing behavior $b$

(Fishbein \& Ajzen, 1975)

Based on the expectancy-value model of attitudes that Fishbein and Ajzen (1975) adopted, it is hypothesized that if a person believes that taking an HIV test will lead to mostly positive outcomes, the attitude to intend to take the test becomes a positive one. If negative outcomes are expected, the attitude becomes a negative one, which will not lead to an intention to perform the behavior. Other things being equal, the more favorable a person's attitude is to an HIV test, the more the person should intend to take it. Conversely, the more unfavorable the person's attitude is, the less the person intends to do so. Although it is possible to consider attitudes as the determinant of the overall favorability of a person's intentions, Fishbein and Ajzen emphasized that attitude was not assumed to determine any given intention. but it influenced the general level of favorability expressed by the person's intentions. 
Ajzen and Fishbein (1980) recommended the semantic differential technique developed by Osgood and his colleagues (1957) to measure attitudes, given that this technique yields a relatively direct measure of a person's attitudinal domains. The semantic differential technique employs a series of adjective pairs on which respondents are asked to evaluate a behavior in question by checking one of the seven sections of a continuum. The adjectives are rated to allow both negative and positive evaluations to be made. The use of bipolar scales to assess evaluation is widely accepted by many researchers, so that people can have either negative or positive evaluations of a particular outcome.

\section{$\underline{\text { Subjective Norm }}$}

A subjective norm is operationalized by Ajzen and Fishbein (1980) as a person`s subjective judgment concerning whether significant others would want the person to perform or not to perform the behavior. Normative beliefs are operationally defined as the person's perception of whether specific referents would want the person to perform the behavior under consideration. Motivation to comply is defined as the person's willingness to comply with the expectations of the specific referents. Although normative beliefs are similar to subjective norms, they are different in that the normative beliefs involve specific individuals or groups rather than generalized important others. A subjective norm is proposed to be a function of a normative belief weighted by the motivation to comply with each of the referents. For statistical analysis, Ajzen and Fishbein suggested that 
subjective norms be assessed in a similar fashion as are attitudes. The formula of the subjective norm can be written as:

$$
S N=\sum_{i=1}^{n} B_{i} m_{j}
$$

SN: subjective norm to behavior

$B_{i}$ : belief that a referent $i$ wants one to do a behavior

$\mathrm{m}_{\mathrm{i}}$ : motivation to comply with referent $\mathrm{i}$

$n$ : number of referents

(Fishbein \& Ajzen, 1975)

The TRA proposes that the more people perceive that important others think they should perform a behavior, the more they will intend to do so. Conversely. if individuals believe that important others think they should not perform a behavior, they will usually not intend to do so. Terry, Gallois, and McCamish (1993) reported success using this conceptualization. In the study of condom use in young heterosexuals, they found that normative beliefs showed significant relationships to intentions and behavior. The participants intending to use a condom differed from non-intenders on their perception of whether other people would want them to perform the behavior. They also reported that participants intending to use a condom on their next sexual encounters were more likely than the non-intenders to perceived that a range of different referents would 
want them to use a condom during their next sexual encounters. Similarly the present study hypothesizes that, other things being equal, people are more likely to intend to take an HIV test if they perceive that important others think they should test for HIV.

\section{$\underline{\text { Intention }}$}

Ajzen and Fishbein (1980) operationally defined intentions as a person's subjective probability judgment of how the person intends to behave. Ajzen (1988) regarded the intention as the most proximal determinant of behavior, reporting high correlations (coefficients ranging from .72 to .96) between a person's intentions and subsequent behavioral actions. A large number of studies in the past evidenced the intention-behavior relationships including studies involving strategy in laboratory games (Ajzen. 1971); decisions of abortion (Smetana \& Adler, 1980): and choosing a candidate in an election (Ajzen \& Fishbein). According to the TRA, people are likely to consider the information available to them, which forms their attitudes and subjective norms. The attitudes and subjective norms then form the intention to perform a behavior. Ajzen and Fishbein pointed out that. assuming appropriate measures are obtained, the attitudinal and normative components should always predict the intention.

\section{Demographic Variables}

Ajzen and Fishbein (1980) explained possible external variables in studies using the TRA: namely. demographic variables. attitudes toward people and 
personality traits. They proposed that the external variables could influence intentions indirectly by influencing either the attitude or subjective norm components. For example, Ajzen and Fishbein reported that women tended to place more emphasis on attitudinal considerations than men for some behavioral intentions which had significant relationships with the attitudinal component. Similarly, people high in authoritarianism may place more weight on subjective norms than those who were low in the trait (Ajzen \& Fishbein).

Gender differences may be influential in health-related behaviors. For example. women were reported to be more likely than men to engage in the following behaviors: health-related information seeking (Feldman, 1966; Nathanson, 1977): use of preventive medical services (Haefner, Kegeles, Kirscht, \& Rosenstock, 1967; Lairson \& Swint. 1978): and asymptomatic checkups (Nathanson. 1977).

In studies of HIV, AIDS, and safer sex behaviors, information about the sexual orientation of the respondents becomes critical. Gallois et al. (1992) found that heterosexual men, heterosexual women and gay men differed in their beliefs about the consequences of their sexual behaviors. For instance, gay men viewed themselves to be more likely to contract HIV than heterosexual people did.

Assuming these past studies relate to the present study and to its population group, the information of the participants" sexual orientation and gender may be critical. Therefore. the present study includes inquiries of age. relationship status, 
ethnic group and sexual orientation in the demographic questionnaires in order to investigate the relationships of these variables with the independent and dependent variables.

\section{Efficacy of the TRA in HIV-Related Studies}

Efficacy of the TRA in predicting HIV preventive intentions and behaviors was suggested in studies of adolescents ${ }^{*}(\underline{N}=155)$ intentions to use condom regularly (Krahe \& Reiss. 1995), gay men's $(\underline{\mathrm{N}}=297$ ) intentions to reduce risky behaviors and their actual behaviors (Cochran. Mays, Caruso, \& Mallon, 1992). and HIV preventive behaviors in gay men $(\underline{N}=19)$, heterosexual high school $(\underline{N}=$ 87). and university ( $\underline{N}=71$ ) students (Fisher, Fisher, \& Rye, 1995). Using multiple regression analyses and some correlation analyses, the three studies supported the TRA as a model of HIV risk reduction. However, Krahe and Reiss hesitated to endorse the impact of the subjective norm components, whereas studies by Cochran et al. and Fisher et al. supported subjective norms as influential predictors of intentions. Krahe and Reiss reported the bivariate regression coefficient of .51 $(\mathrm{p}<.001)$ from the attitude, while they reported that the coefficient from the subjective norm was only marginal (bivariate $\underline{\mathrm{R}}=.16, \underline{\mathrm{p}}<.05$ ).

Besides attitudes and subjective norms, Krahe and Reiss (1995) included two additional variables (fear of AIDS and AIDS knowledge measures) in predicting behavioral intentions. However, the two variables failed to play a significant role in the predictions. Thus, the attitudinal contributions to HIV 
preventive intentions played the major role since they have exceeded the effects of fear. which many people considered as the major factor in HIV-related measures.

As for the relationships between people's behavioral intentions and their actual behaviors, Cochran et al. (1992), and Fisher et al. (1995) reported relatively supportive correlations. Condom use in gay men was significantly correlated with their intentions $(\underline{\mathrm{r}}=.31, \underline{\mathrm{p}}<.001)($ Cochran et al.). Fisher et al. reported a significant correlation between intention and behavior in gay men and heterosexual students. The correlation coefficients ranged from .40 to 60 .

However, the efficacy of the TRA in HIV testing intentions has been rarely investigated. Whether people's attitudes toward HIV testing and their perceptions of social pressure toward the tests influence their intentions to take the tests has not been examined extensively.

\section{People's Reactions to HIV Tests}

Few researchers have attempted to understand attitudes toward HIV testing among members of the general adult population. Most research has focused on gay and bisexual populations and has examined motives for testing (Lyter et al., 1987; Seigel, Levine, Brooks. \& Kern. 1989) and psychological responses to the test (Jacobson, Perry, \& Hirsch, 1990). Even fewer studies have focused on people's intentions to take HIV tests, especially in heterosexual populations.

According to Hardy and Dawson (1990) who cited the National Health Interview Survey (NHIS), a cross-sectional survey of general population of the 
Linited States conducted in 1988, approximately one in six adults in the United States had been tested for HIV. The majority of them indicated blood donation as the HIV testing method. Arguably, some included blood donation as a method of HIV testing. However, this means of testing can be justified because some people actually intended to test their HIV status through blood donations (Hardy \& Dawson). Hardy and Dawson summarized some demographic data of the people who had been tested for HIV (see Table 1). The survey revealed that of the total sample. $20 \%$ of the male and $13 \%$ of the female participants had been tested for HIV. Thirty-five percent of the individuals of high-risk groups had taken the tests, as compared to $16 \%$ of those in low-risk groups. However, the majority of those in low-risk groups underwent blood donation (74\%) to learn their HIV status. Highrisk individuals (46\%) were more likely than their counterparts (14\%) to test voluntarily in clinics and hospitals.

Myers et al. (1993) investigated factors affecting gay and bisexual men's decisions and intentions to seek HIV testing. Fifty-three percent of their sample had been tested for HIV at least once. Of those who had been tested, 26\% tested HIV-positive. All respondents were asked about their intentions to be tested the following year. Of those who had not been tested previously, $30 \%$ indicated an intention to be tested, compared with $70 \%$ of those who had tested negative and $60 \%$ of those who had tested positive. In addition, $34 \%$ of those not tested were unsure about being tested in the next year, compared with $13 \%$ of those who had 
Table 1

Percentage of adults who have already tested and the circumstances of the testing

\begin{tabular}{|c|c|c|c|c|}
\hline & & \multicolumn{3}{|c|}{ Circumstances of the testing } \\
\hline Group & Tested $^{\mathrm{a}}$ & Blood Donation & Voluntary $^{b}$ & $\begin{array}{l}\text { Other/non- } \\
\text { voluntary }\end{array}$ \\
\hline Total & 17 & 73 & 16 & 14 \\
\hline \multicolumn{5}{|l|}{$\operatorname{Sex}$} \\
\hline Male & 20 & 72 & 15 & 16 \\
\hline Female & 13 & 74 & 17 & 10 \\
\hline \multicolumn{5}{|l|}{ Race/Ethnicity } \\
\hline White & 17 & 76 & 14 & 12 \\
\hline Black & 14 & 55 & 26 & 23 \\
\hline Hispanic & 14 & 58 & 22 & 23 \\
\hline \multicolumn{5}{|l|}{ Age } \\
\hline $18-29$ & 24 & 70 & 17 & 17 \\
\hline $30-49$ & 20 & 74 & 16 & 12 \\
\hline Over 49 & 7 & 75 & 12 & 10 \\
\hline \multicolumn{5}{|l|}{ Risk Behavior } \\
\hline High-risk & 35 & 40 & 46 & 14 \\
\hline Low-risk & 16 & 74 & 14 & 14 \\
\hline
\end{tabular}

Note. 1988 National Health Interview Survey, cited by Hardy and Dawson (1990). ${ }^{a}$ Bolded numbers represent the percentages of those tested before.

${ }^{b}$ Voluntary includes people who have tested voluntarily in clinic and hospitals. 
previously tested negative and $7 \%$ of those who had tested positive. Some significant findings were reported. Gay men (56\%) were more likely to be tested than bisexual men $(42 \%)$. They found that perception of the personal risk of contracting HIV was significantly related to test decisions. Of the respondents who were "almost certain" that they had a high probability of contracting HIV, $68 \%$ had been tested. Of those who had lower scores on perceived risk questions, $47 \%$ had been tested. Contrary to predictions, education level, age and income were not related to the decisions to be tested.

Meadows, Catalan, and Gazzard (1993) investigated which factors predicted HIV testing intentions of women who were attending an antenatal clinic in London. Among the variables studied, age, marital status, social factors, and HIV knowledge showed significant results. They concluded that less knowledgeable individuals were more likely to express intentions to take the HIV test. Younger women who were single were found to have stronger intentions to take the tests. Multivariate analysis confirmed that among the strongest factors in the prediction of intentions to be tested were perceived benefit of the test to themselves and their sexual partners.

Lupton, McCarthy, and Chapman (1995) investigated the motives of heterosexual college students to take HIV tests in Australia. They found that the individuals took HIV tests because they were exhorted by others to do so for various reasons. For example, many men were motivated to have the test solely as 
an administrative measure at the behest of their female partners, while females took the tests to encourage their partners to take the test. Having the test result was considered as a nice reassurance or a proof of cleanliness, providing an opportunity to say to one's partner that they are negative. In addition, the authors reported that the HIV tests were taken primarily by low-risk individuals who look for a peace of mind by taking an HIV test. The government officials in Australia are concerned about the rising cost to the testing for low-risk individuals. One solution may be the new HIV tests that are in use in the United States, making persons pay for the tests by themselves.

\section{New HIV Tests}

Despite the fact that the conventional HIV antibody test was accurate and easy to conduct, many people did not take advantage of its availability. A decade passed since the development of original HIV tests, and alternative methods came into the society. In 1996, two new types of HIV testing received the approval by the FDA. One is called "Orasure" developed by Epitope in Oregon. It is a salivabased collection device for HIV antibody screening. It has been approved by the FDA as a physician-use device. The other is a home-blood collection kit, also approved by the FDA. At least three companies developed the product, Direct Access Diagnosis (New Jersey), a subsidiary of Johnson and Johnson; Chem Trak (California): and Anonymous Testing Services (Illinois) (Leary, 1994). As of March 1997, the Direct Access Diagnosis is the only manufacture that has 
received an approval for sales at pharmacies in the United States after several months of experimentation. Other manufactures of the products are seeking an approval of the sales as an over-the-counter (OTC) home-specimen kit. Currently, the application is heading toward approval (Bayer et al., 1995).

When first proposed seven years ago, the new HIV testing methods met with virtually unanimous opposition by the American Medical Association (AMA), the CDC, and gay communities (Bayer et al., 1995; Marwick, 1995). They were skeptical about whether a lay person could reliably and safely perform the test and interpret the results without benefits of medical advice and professional counseling. However, the benefits of the new HIV testing methods started to be reported. The past surveys on this issue revealed that people in general were in favor of the new methods (Phillips, Flatt, Morrison, \& Coates, 1995; Freundlich \& Hamilton, 1996). Recently, the CDC and other authorities have shifted their opinion to a more favorable one for the producers of the products. The expanded methods of HIV testing may increase the availability of HIV testing to people who otherwise do not choose to use the conventional HIV tests. Freundlich and Hamilton reported that with people able to take the tests comfortably in their own homes, up to 30 million Americans might buy a home HIV test.

A few researchers studied people's opinions about the new homecollection testing methods. Overall, they reported that people generally favored the home-collection kit over the conventional tests. Phillips et al. (1995), and 
Freundlich and Hamilton (1996) reported the results of the 1992 National Health Interview Survey (NHIS). It reported that $29 \%$ of the respondents to the NHIS stated that they would be "very" or "somewhat" likely to use home HIV tests if they were available. Three quarters of this group said that they had never been tested if blood donation was excluded. Forty-two percent of the respondents at risk, many of them minorities, said that they would be very or somewhat likely to use home tests. Sixty-three percent of this group said that they had never been tested before. Twenty-two percent of all respondents and $31 \%$ of those at risk said they would choose a home test over other testing alternatives. The regression analysis revealed the characteristics of the individuals who would be likely to take home HIV tests. It reported that people were more likely to take home HIV tests if they were younger, non-white, males, with less education, or with less income. In addition. they were more likely to perceived themselves less vulnerable to AIDS and less likely to have been aware of where to go for an HIV test.

\section{Description of the HIV Tests}

The present study will ask participants' preferences in HIV testing procedures. Assuming there are four methods available, this study highlights some important differences between the four methods as the factors to testing. The following are the descriptions of the four HIV testing methods that are already in use or being discussed for future use. 
Intention to take HIV tests 26

(1) Conventional blood-based HIV antibody test (Vargo, 1992)

This is, to date, the most common HIV test that is currently conducted in physician`s offices and HIV (or STD) testing clinics where people visit and receive pre- and post-test counseling. After the pre-test counseling, a phlebotomist collects the blood sample with needles from a vein in the arm of a person. After one or two weeks (depending on the location), the person comes back and receives the result. followed by post-test counseling. The length of the counseling sessions differs significantly depending on the location and the personal situations of the individual. The cost of the test also differs depending on the testing sites. The entire process remains anonymous or confidential. The test is accurate in more than $99 \%$ of the cases.

(2) Saliva-based HIV antibody test

This method is currently used only by the physicians and clinic personnel. However, the manufacturer of this test has been seeking approval for home use and possibly OTC use. Currently, the procedure is similar to the conventional test, except that this testing uses a pain-free device to collect a saliva sample rather than a blood sample.

The device is like a toothbrush and is placed between the lower gum and the cheek for about two minutes. Although it requires a little scrub against the gum. it is painless. There have been some complaints of short-term negative aftertaste. The device is then put into a small tubed culture to be sent to the laboratory. 
It is similar to the conventional HIV tests in terms of the waiting period, counseling, accuracy (about 99\%), cost, and the anonymity and confidentiality. (3) Blood-based home collection kit (Bayer et al.. 1995: Marwick, 1995; Phillips et al., 1995; Freundlich \& Hamilton, 1996)

This test requires individuals to prick their fingers using a lance provided in the kit. A few drops of blood are absorbed by a special paper that carries a unique identification number. This test kit is currently available, and its sampling process can take place anywhere. Once collected. the sample needs to be sent to the company-provided laboratory, where it is screened for HIV antibodies using an enzyme linked immunosorbent assay. If the test comes out positive, at least one confirmatory test will be done as in other methods. A week later, the tested individual calls the laboratory, punches in the identification number on the telephone, and is informed of the result. The calls are handled by an automated machine (i.e. not a person-to-person conversation). Those who tested negative are expected to listen to recorded information that teaches them the meaning of the result and offering them the option of speaking to a counselor who would provide referrals to follow-up clinical services and social service agencies. Infected persons have the option of follow-up telephone counseling for a specified number of sessions. This entire process remains anonymous. The price for the test kit is reported to be from 30 to 40 dollars. The accuracy is the same with the conventional method. approximately $99 \%$. 
(4) Assumption of the saliva-based home collection kit

Epitope, the company that developed the saliva-collection device, is hoping that the same procedures available for blood-based home collection kits will be available for saliva-based home collection kits.

The present study focuses on four factors that are the major differences between the four methods: fluid sample to be taken (blood or saliva); location of sample-taking (clinic or home); absence or presence of counseling: and the method of receiving the test result (face-to-face or by telephone). Although the cost of the test is an obvious difference, it differs so greatly depending on the testing methods and testing locations that it is not included as a variable of interest in the questionnaire. 


\section{Present Study}

Despite the popularity for social scientists to research HIV and AIDS, the HIV testing intentions, surprisingly, have not been dealt with in scientific studies. Health-related studies have heavily concentrated on preventive health behaviors related to HIV transmission, leaving the screening intentions and behaviors unexplained. Highly threatening conditions like HIV and AIDS naturally necessitate investigations at a social and personal level, not only in terms of prevention but aiso in terms of screening intentions and behaviors. The present study. therefore. intends to explore rather a new area of investigation. However. becaulse of this reason, the major focus of this study is to explore broader concepts of HIV testing intentions, consequently introducing some ideas for later researchers to study in a deeper degree.

\section{$\underline{\text { Antecedents }}$}

A broad contextual picture of the variables is shown in Figure 3. Since there has not been any established measure to examine HIV screening intentions, this study attempts to employ rather primitive steps to investigate the relationships between the antecedents and the dependent variable. Therefore, although the measures of the present study are based on the guidelines of Ajzen and Fishbein (1980). some modifications are applied in the analysis. Each context in attitudes and each referent in subjective norms are examined individually as an attitude score and a subjective norm score, respectively. The rationale behind the 


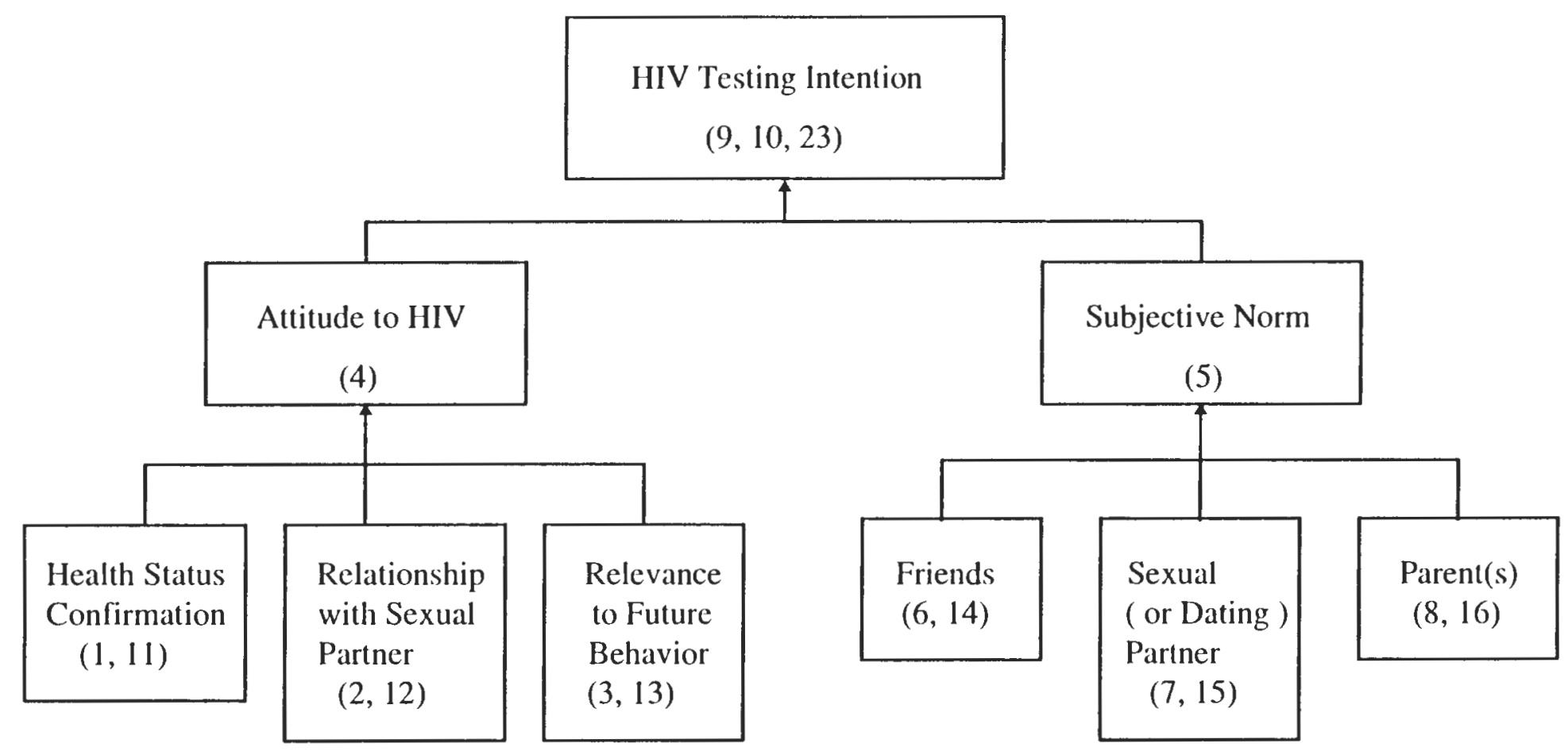

Figure 3. Summary of contexts of the variables for the present study.

Inside the parentheses are the question numbers used in the questionnaire. 
modification is on the researcher's desire to investigate different contextual settings for attitudes and different referents for subjective norms, which eventually may lead to the specification of an attitudinal context and referent that best relate to intentions to take HIV tests. However, if an internal consistency is observed in the independent variables, the analysis is executed as the guidelines suggest (see Figure 2).

As shown in Figure 3, attitude are viewed in the following contexts; health status confirmation, relationship with dating or sexual partners, and relevance to future health behavior. These contexts are selected based on the study by Meadows and colleagues (1993) that found the perceived benefits to themselves and their partners were strong factors in predicting HIV testing intentions for women in London. A question on health status confirmation asks whether taking an HIV test is perceived to be an important and effective way to verify health status. A question on relationship asks whether taking an HIV test promotes or secures one's relationships with a partner. A question on relevance to future health behavior asks how important knowing an HIV status is to one's future health. Scores of behavioral beliefs and outcome evaluations, in accordance with specific contexts, are matched to form three attitude scores which are consequently added to form one attitude score.

Subjective norms employ three specific referents; friends, sexual or dating partner (or future partner), and parent(s). Each question asks how much a referent 
thinks one needs to take an HIV test. Subsequently, one's motivation to comply with each referent are matched to produce three subjective norm scores. As in attitude measure, the sum of the three scores becomes the score of the subject norm.

$\underline{\text { Goals }}$

The present study has two major goals. First, it attempts to evaluate the utility of the TRA in predicting intentions to take an HIV test. The relative importance of attitudes and subjective norms in predicting intentions to take an HIV test is investigated. The second objective is to systematically examine consumer preferences for available HIV tests and the tests that are currently under discussions in the government. Whether the new tests will attract college students is investigated in this process. In addition, whether college students' intentions to take HIV tests change if they are provided with some methodological choices in the testing procedure is examined.

Hypotheses.

\section{H1: Individuals' attitudes and subjective norms will predict intentions} to take an HIV test. That is, individuals who indicate more favorable attitudes toward an HIV test and who think that important others think they should take the test will be likely to indicate higher intentions to take the test. Conversely, those who indicate less favorable attitude and who think that important others think they do not need to take the test will be less 
likely to intend to test for HIV.

H2: Individuals will be more likely to prefer factors that are characteristic of the new HIV tests to those of the conventional tests. That is, more individuals are expected to choose home as the preferred location of sampling over clinic, saliva as a preferred sample taken over blood, and by telephone as a preferred means of receiving the result over in face to face with a clinician or a physician. It is also expected that more individuals would prefer not to have counseling.

H3: Individuals will be more likely to intend to take an HIV test which inchudes their preferences as compared to their notion of a general HIV test. The scores obtained to a question that asks about participants' intentions to take an HIV test that incorporates their procedural preferences would be greater than the scores for general intentions to take an HIV test. Thus, the testing method of the latter is dependent on participants conception of HIV testing. If this hypothesis is supported, it would indicate that parts of the reasons they have not taken the test lie in the testing methodology.

The relationships between demographic characteristics and intentions to take HIV tests are also investigated. In addition to testing these hypotheses, relationships between demographics and preferences for testing procedures will also be explored. It is important to note that the present study asks about intentions 
to take an HIV test. not the behavior of actually getting the test. Based on Ajzen and Fishbein`s (1980) assumption that intentions are a necessary precursor to behaviors, and that the study design is cross-sectional, this is deemed appropriate. 
Method

\section{$\underline{\text { Participants }}$}

One Hundred ninety university undergraduate and graduate students at Portland State University (Portland, Oregon) voluntarily participated in this study. Participation was requested in classes where most of the participants received extra credit for taking part in this study. Sixty-one respondents $(32 \%)$ were male with an average age of 24.4 years, while $126(66 \%)$ were female with an average age of 26.2 years. Three persons did not respond to the question of age. The respondents ranged in age from 19 to 52 years old with a mean age of 25.6 and a median age of $22(\underline{\mathrm{SD}}=6.9)$. The majority of the respondents were White $(78 \%)$, with fewer respondents of other races or ethnicities (African American, Hispanic, Asian/Pacific Islander, and other $)(2 \%, 6 \%, 10 \%$, and $4 \%$, respectively). With respect to sexual orientation. 177 respondents $(94 \%)$ indicated that they were heterosexual, four (2\%) homosexual, six $(3 \%)$ bisexual and one indicated other sexual orientation. Three persons did not respond to the sexual orientation question.

One hundred twenty-one $(65 \%)$ respondents indicated that they had regular partners such as a husband, wife, boyfriend or girlfriend at the time of the data collection. Among them, $35(29 \%)$ were legally married, $30(25 \%)$ were living with their partners as married, and $56(46 \%)$ had partners but were not cohabiting. Sixty-six $(35 \%)$ respondents were single and had no partners at the time. Three 
persons did not respond to the relationship status question.

\section{Measures}

A questionnaire was used, containing measures of attitudes toward HIV tests. subjective norms related to HIV tests, intentions to take HIV tests, preferences for HIV testing methods, and demographic questions (see Appendix). The questionnaire was constructed based on guidelines from Fishbein and Ajzen (1975; Ajzen \& Fishbein, 1980). Semantic differential scales were employed with some revisions in end-point wording.

Attitudes. Three items asked participants' judgments of the behaviors (behavioral belief). Participants were asked to circle one number of a 7-point semantic differential scale ranging from (1) "definitely uncertain" to (7) "definitely certain." For example, participants were asked to indicate their response on a continuum similar to the one below:

How certain are you that taking an HIV test is an effective way to make sure of your health status?

$\begin{array}{ccccccc}1 & 2 & 3 & 4 & 5 & 6 & 7 \\ \text { Definitely } & & & & & & \\ \text { Uncertain } & & & & & \text { Definitely } \\ \text { Certain }\end{array}$

Three additional items asked participants' evaluations of particular outcomes (outcome evaluation). A question of this type read. "Taking an HIV test to make sure of one's health status is." and participants were asked to respond on a scale 
raging from (1) "definitely bad" to (7) "definitely good."

The products of each individual behavioral belief and its corresponding outcome evaluation were the antecedents of attitudes for an individual. One direct question that asked about participants' attitudes toward HIV testing was included; "What is your attitude toward your taking an HIV test?" A 7-point scale was again used for this question. This item was designed to be used as an attitude score in the event that the previous scores failed to reliably measure the desired attitude. Such a substitution was proposed by Ajzen and Fishbein (1980).

Subjective Norms. Three items measured participants' normative beliefs, that is. the extent to which participants perceived that important others think that they should take an HIV test. Each item deals with different referents (dating or sexual partners, parent(s), and friends). Participants responded on a 7 -point semantic differential scale, as used in the measurement of attitudes. Three additional items asked them to rate their motivation to comply with each referent. Each item asked how likely the participants generally do what each referent person wanted of them. A question for normative beliefs was, "What does your dating or sexual partner think about whether you should take an HIV test?" Responses were made on a 7-point scale similar to the ones used in the attitude sections, ranging from (1) "think I definitely do not need to" to (7) "think I definitely need to." A question asking about the participants' motivation to comply with a referent read. "In general, how likely is it that you would do something your dating or sexual 
partner thought you should do?" The scale ranged from (1) "definitely unlikely" to (7) "definitely likely."

The subjective norm score was computed by summing the products of the normative belief scores and the motivation to comply scores. As in the attitude section, this section included a direct question asking about subjective norms; "What do people who are important to you think about whether you should take an HIV test?" Participants were expected to respond on a 7-point scale, ranging from (1) "think I definitely not need to" to (7) "think I definitely need to." The score was prepared to be used as a subjective norm score for an individual if the previous three scores lacked in internal consistency.

Intentions. Two items assessed the participants' intentions to take an HIV test in the future. To a question asking, "Do you intend to take an HIV test in the future?," participants were expected to respond on a scale similar to that used for attitudes and subjective norms, ranging from (1) "definitely no" to (7) "definitely yes." The other question read, "If an important person advises you to take an HIV test. will you be tested?" Although this question seems to be particularly related to subjective norms, it was considered to be an appropriate intention question because the influence of a close person on one's HIV testing decision was reported to be significant by Meadows. Catalan, and Gazzard (1993).

Preferences. Participants' preferences for four procedural factors related to HIV testing were obtained. Participants were asked to check one of the two 
options with respect to each procedural factor. The factors and their options were body fluid sample (blood or saliva), location of sample taking (clinic or home), counseling (prefer to have or not to have) before and after HIV tests, and means of obtaining the test result (by face-to-face or by telephone). For the counseling factor, two additional questions were included. One question asked about participants' preferences for post-test counseling if they were HIV-negative, and the other asked about preferences for post-test counseling if they were HIVpositive. Participants were also asked to predict their intentions to take an HIV test if the test incorporated all the conditions of testing that they preferred. In addition, an open-ended question was included to ask why the respondents chose the options they did.

Demographic questions (age. sex, current relationship status, sexual orientation. and ethnic group) were also asked. Additionally, questions asking about participants" perceptions of their risk for HIV, their perception of the risk of HIV in those who are the same age, and their concern about HIV and AIDS as a social problem were included with a 4-point scale ranging from $(0)$ " not at all" to (3) "extremely." Their experiences of HIV testing (i.e., previously tested or not) were also asked for comparative reasons.

\section{$\underline{\text { Procedure }}$}

The questionnaires were handed to participants along with an introduction page and a cover sheet. explaining the content of the study, the anonymity of the 
Intention to take HIV tests 40

study, and the participants freedom to withdraw from the study. Participants were expected to keep the cover sheet. Participants were allowed to take the questionnaires outside classroom. After the questionnaires were completed, they were collected for analysis and the participants were debriefed and thanked. 


\section{Results}

\section{Previous HIV Testing Experience}

Sixty-one respondents (33\%) indicated that they have been tested for HIV at least once in the past. Approximately $21 \%$ of male respondents and $38 \%$ of female respondents have taken HIV tests previously. About $32 \%$ of heterosexual respondents indicated that they had been tested for HIV. One of the three homosexual participants and each of the three bisexual respondents had been tested previously. About $23 \%$ of legally married respondents. $33 \%$ of cohabiting respondents, $43 \%$ of non-cohabiting respondents, and $29 \%$ of respondents who did not have a partner also reported being tested.

\section{$\underline{\text { Reliability Analysis }}$}

The scale measuring the attitudes toward HIV testing had internal consistency (Cronbach's $\alpha=.84$ ). The antecedents of the subjective norms also were internally consistent $(\alpha=.91)$. Therefore, the attitude and subjective norm scores were calculated in the manner suggested by Ajzen and Fishbein (1980). However, the two intention questions did not have good reliability $(\alpha=.58)$. Thus, the intention questions, one of which asked directly about intentions to take an HIV test in the future (named "intention A") and the other that asked about intentions if important others advised them to take the test (named "intention B"), were examined individually. 


\section{Variables of the Theory of Reasoned Action (TRA)}

Means and standard deviations for the variables of the TRA are presented in Table 2. Attitude scores were computed by multiplying each behavioral belief item by its corresponding outcome evaluation item and summing the products across the three items. Similarly, the scores for the subjective norm were calculated by summing the products of each normative belief item and its corresponding motivation-to-comply item. For comparative reasons, the attitude and the subjective norm variables that were scored from a direct question are also listed, and are represented by "Att" and "SN" respectively.

For the descriptive statistics, as well as for some other subsequent analyses. findings are reported separately for five groups: the total sample (Total), the male respondents (Male), the female respondents (Female), the respondents with previous HIV testing experience (Tested), and the respondents without testing experience (Not Tested).

\section{Correlational Analyses}

Prior to testing the predictability of the TRA for HIV testing intentions, intercorrelations among the variables shown in Figure 2 were examined. Table 3 presents Pearson's correlation coefficients between the predictors (attitude and subjective norm) and testing intentions. Attitude and subjective norm significantly correlated with intention " $\mathrm{A}$ " $(\underline{\mathrm{r}}=.35, \mathrm{p}<.001$ and $\underline{\mathrm{r}}=.63 . \mathrm{p}<.001$, respectively $)$ and with intention " $\mathrm{B}$ " $(\underline{\mathrm{r}}=.41 . \mathrm{p}<.001$ and $\underline{\mathrm{r}}=.35, \mathrm{p}<.001$, respectively $)$. As 
Table 2

Means and Standard Deviations of Variables of the Theory of Reasoned Action

\begin{tabular}{|c|c|c|c|c|c|}
\hline Variables & $\begin{array}{l}\text { Total } \\
N=190\end{array}$ & $\begin{array}{l}\text { Males } \\
n=61\end{array}$ & $\begin{array}{c}\text { Females } \\
n=126\end{array}$ & $\begin{array}{l}\text { Tested } \\
n=61\end{array}$ & $\begin{array}{l}\text { Not Tested } \\
n=124\end{array}$ \\
\hline \multirow[t]{2}{*}{ Attitude ${ }^{a}$} & 89.99 & 84.51 & 93.15 & 99.30 & 84.87 \\
\hline & $(34.0)$ & $(34.0)$ & $(34.0)$ & $(30.9)$ & $(34.8)$ \\
\hline \multirow[t]{2}{*}{ Subjective norm ${ }^{a}$} & 45.78 & 44.07 & 46.90 & 62.32 & 37.95 \\
\hline & $(32.5)$ & $(32.6)$ & $(32.7)$ & $(36.1)$ & $(28.0)$ \\
\hline \multirow[t]{2}{*}{$\mathrm{Att}^{\mathrm{b}}$} & 5.85 & 5.66 & 5.95 & 6.52 & 5.52 \\
\hline & $(1.5)$ & $(1.5)$ & $(1.4)$ & $(.94)$ & $(1.5)$ \\
\hline \multirow[t]{2}{*}{$S N^{b}$} & 3.15 & 3.13 & 3.17 & 4.14 & 2.65 \\
\hline & $(1.9)$ & $(2.0)$ & (1.9) & $(2.0)$ & $(1.7)$ \\
\hline \multirow[t]{2}{*}{ Intention $\mathrm{A}^{\mathrm{b}}$} & 4.40 & 3.92 & 4.65 & 5.49 & 3.84 \\
\hline & $(2.1)$ & $(2.2)$ & $(2.1)$ & $(1.9)$ & $(2.1)$ \\
\hline \multirow[t]{2}{*}{ Intention $\mathrm{B}^{\mathrm{h}}$} & 5.61 & 5.44 & 5.73 & 6.12 & 5.38 \\
\hline & $(1.6)$ & $(1.4)$ & $(1.6)$ & $(1.3)$ & $(1.6)$ \\
\hline
\end{tabular}

Note. $A t t=$ attitude score asked directly. $\mathrm{SN}=$ the subjective norm score asked directly. Inside parentheses are standard deviations. ${ }^{\text {a }}$ Scores ranged from 3 to $147 .{ }^{\text {b }}$ Scores range from 1 to 7. 
Table 3

Intercorrelations Among the TRA Variables

\begin{tabular}{|c|c|c|c|c|c|c|c|c|c|}
\hline Variables & 1 & 2 & 3 & 4 & 5 & 6 & 7 & 8 & 9 \\
\hline 1. Attitude & $\cdots$ & & & & & & & & \\
\hline 2. $\mathrm{HSC}$ & $.84 * *$ & -- & & & & & & & \\
\hline 3. Relation & $.89 * *$ & $.63 * *$ & --- & & & & & & \\
\hline 4. Future Health & $.88 * *$ & $.62 * *$ & $.68 * *$ & $\cdots$ & & & & & \\
\hline 5. Subjective Norm & $.49 * *$ & $.34 * *$ & $.48 * *$ & $.45^{* *}$ & -.. & & & & \\
\hline 6. Friends & $.41 * *$ & $.29 * *$ & $.40 * *$ & $.37 * *$ & $.93 * *$ &..- & & & \\
\hline 7. Partner & $.47 * *$ & $.32 * *$ & $.47 * *$ & $.43 * *$ & $.94 * *$ & $.84 * *$ & --- & & \\
\hline 8. Parent & $.45 * *$ & $.33 * *$ & $.44 * *$ & $.40^{* *}$ & $.91 * *$ & $.75 * *$ & $.77 * *$ & --- & \\
\hline 9. Intention $A$ & $.35 * *$ & $.22 *$ & $.37 * *$ & $.31 * *$ & $.63 * *$ & $.55^{* *}$ & $.60^{* *}$ & $.58 * *$ & --- \\
\hline 10. Intention B & $.41^{* *}$ & $.32 * *$ & $.44^{* *}$ & $.32 * *$ & $.35 * *$ & $.29 * *$ & $.32 * *$ & $.30 * *$ & $.43 * *$ \\
\hline
\end{tabular}

Note. HSC $=$ Health Status Confirmation context. ${ }^{*} \mathrm{p}<.01 .{ }^{* *} \mathrm{p}<.001$. 
shown in Table 3, the antecedents of the attitude were significantly and consistently correlated with the attitude (its coefficients ranging from .84 to .89 ), and with intention " $\mathrm{A}$ " (ranging form .22 to .31) and intention " $\mathrm{B}$ " (ranging from .32 to .44$)$ for the total sample. Similarly, the antecedents of the subjective norm were significantly and consistently correlated with the subjective norm (coefficients ranging from .91 to .94), and with intention A (ranging from .55 to .60 ) and intention B (from .29 to .32 ).

\section{Multiple Linear Regression Analyses}

Multiple Linear Regression (MLR) analyses were performed to test the first hypothesis which stated that respondents’attitudes and subjective norms toward HIV testing would predict their testing intentions. Both intention measures (i.e., $A$ and $B)$ were significantly predicted by the antecedents $(\underline{R}=.64, \underline{p}<.001$ for intention $\mathrm{A}$; and $\underline{\mathrm{R}}=.42, \underline{\mathrm{p}}<.001$ for intention $\mathrm{B}$ ). Thus, the findings basically support the TRA. For the total sample, $41 \%$ of the variance in intention A was accounted for by attitudes and subjective norm, while $18 \%$ of the variance in intention B was explained by the antecedents.

The empirical weights ( $\underline{B}$ and $\beta s$ ) of the antecedents for the total sample and their significance levels are presented in Table 4. As shown in Table 4, the large $\mathrm{R}$ in the MLR analysis with intention $\mathrm{A}$ as the dependent variable was almost entirely due to the predictive power of the subjective norm component $(\beta=.61, \mathrm{p}$ 
Table 4

Simultaneous Multiple Linear Regression Analysis of Attitude and Subjective

Norm on Intention

\begin{tabular}{|c|c|c|c|c|}
\hline Antecedents and Intentions & $\underline{\mathrm{B}}$ & $\beta$ & T -score & P-value \\
\hline \multicolumn{5}{|l|}{ Intention $\mathrm{A}$} \\
\hline Attitude & .0026 & .0415 & 0.62 & .536 \\
\hline Subjective Norm & .0410 & .6140 & 9.17 & .000 \\
\hline \multicolumn{5}{|l|}{ Intention B } \\
\hline Attitude & .0126 & .2763 & 3.52 & .000 \\
\hline Subjective Norm & .0100 & .2103 & 2.68 & .008. \\
\hline \multicolumn{5}{|c|}{ Note. $\underline{R}=.64$ for Intention $A . \underline{R}=.42$ for Intention $B$. } \\
\hline \multicolumn{5}{|c|}{ Intention A variable directly asked respondents' intentions to take an } \\
\hline \multicolumn{5}{|c|}{ HIV test in the future. Intention B asked about their intentions to take } \\
\hline
\end{tabular}


$<.001)$. The weight of the attitude on intention $\mathrm{A}$ was not significant $(\beta=.04, \mathrm{p}>$ $.05)$. Although the weights of the antecedents in the analysis with intention B as the dependent variable were both significant $(\beta=.28, \mathrm{p}<.001$ for attitude, and $\beta=$ $.21 . \mathrm{p}<.01$ for subjective norm), the coefficient of determination (or R-squared) was too low to emphasize the prediction of intention by attitudes and subjective norms. Therefore. for further analyses, the intention A measure that directly asked about respondents ${ }^{\circ}$ testing intentions was used as the measure of intention levels.

The satisfactory predictive power of subjective norms on intentions is also seen in the bivariate regression weights and coefficients on intention $\mathrm{A}$. The bivariate regression coefficient for subjective norms $(\underline{R}=.63, \underline{p}<.001)$ almost matched the multiple regression coefficient $(\underline{R}=.64, \underline{p}<.001)$. However, attitudes alone also significantly predicted intentions (bivariate $\underline{\mathrm{R}}=.35, \mathrm{p}<.001$ ), but with a smaller predictive power than subjective norms $(\beta=.35, \mathrm{p}<.001$ for attitudes and $\beta=.63, p<.001$ for subjective norms).

\section{Investigation of Antecedents of Attitudinal and Subjective Norm Components}

In order to investigate the predictive power of attitudes and subjective norms on testing intentions in contextual pictures, a series of bivariate regression analyses were performed with each context of attitudinal component (or antecedent of the attitude) and each referent of subjective norm component (or antecedent of the subjective norm) as the predictors of intentions. The regression 
coefficients are presented in Table 5 along with the multiple regression coefficients with all three contexts and all three referents as the set of predictors. Each context of the attitude component is the product of a behavioral belief and an outcome evaluation measure, while each referent of the subjective norm is the product of a normative belief and a motivation-to-comply measure. All three subjective norm referents (friends, dating/sexual partner and parent) had significant regression coefficients for intention (see Table 5).

The regression coefficients in the attitude component, although much less than those in the subjective norm component, were significant. Overall, the multiple regression coefficients were significant in the total sample $(\underline{R}=.38, \underline{p}<$ $.001)$.

\section{Perceived Risk to HIV and HIV Concern Level}

Mean scores and standard deviations of the level of perceived risk of the respondents and their level of concern about HIV and AIDS as a social problem are presented in Table 6 . Both scores were measured using a 4-point scale ranging from (0) "not at all" to (3) "extremely at risk" or "extremely concerned." Overall, the respondents scored low on the perceived risk item. Majority of the respondents indicated their risks to HIV as "not at all at risk" (38\%) or "slightly at risk" (59\%). It can be compared with the scores for an item that asked the perception of risk for others of the same age. The means and standard deviations are also shown in Table 6. Unlike the perception of their own risk to HIV. the respondents indicated higher 
Table 5

Contexts of Attitude Scales (belief X evaluation) as Predictors of Attitude and Referents (normative belief X motivation to comply) as Predictors of Subjective norms: Bivariate and Multiple Regression Coefficients (Regressed on Intention "A")

\begin{tabular}{lccc}
\hline \multicolumn{1}{c}{ Variables } & Total & Male & Female \\
& $(\mathrm{N}=190)$ & $(\mathrm{n}=61)$ & $(\mathrm{n}=126)$ \\
\hline Attitude Contexts & & & \\
Health Status Confirmation & $.220 * *$ & .192 & $.195^{*}$ \\
Partner Relationship & $.369 * * *$ & $.405^{* *}$ & $.367 * * *$ \\
Future Health Behavior & $.306 * * *$ & $.254^{*}$ & $.282 * *$ \\
All three contexts (multiple) & $.379 * * *$ & $.418 *$ & $.375 * * *$
\end{tabular}

Subjective Norm Referents

$\begin{array}{llll}\text { Friends } & .554 * * * & .662 * * * & .517 * * * \\ \text { Partner } & .597 * * * & .752 * * * & .549 * * * \\ \text { Parent(s) } & .575 * * * & .622 * * * & .561 * * *\end{array}$

All three referents (multiple) $\quad .638 * * * \quad .754 * * * \quad .604 * * *$ Note. $* \mathrm{p}<.05 . * * \mathrm{p}<.01 . * * * \mathrm{p}<.001$. 
Table 6

Means and Standard Deviations of Perceived Risk and Concern About HIV/AIDS as a Social Problem

\begin{tabular}{cccccccc}
\hline Subgroups & \multicolumn{2}{l}{ PR For Themselves $^{\mathrm{a}}$} & & \multicolumn{2}{l}{ PR For Others $^{\mathrm{a}}$} & & \multicolumn{2}{c}{ Concern About HIV $^{\mathrm{a}}$} \\
& $\underline{\mathrm{M}}$ & $\underline{\mathrm{SD}}$ & $\underline{\mathrm{M}}$ & $\underline{\mathrm{SD}}$ & $\underline{\mathrm{M}}$ & $\underline{\text { SD }}$ \\
\hline Total $(\mathrm{N}=190)$ & 0.64 & .53 & 1.97 & .70 & 2.21 & .80 \\
Male $(\mathrm{n}=61)$ & 0.57 & .53 & 1.80 & .60 & 1.82 & .89 \\
Female $(\mathrm{n}=126)$ & 0.68 & .53 & 2.06 & .73 & 2.39 & .68 \\
Tested $(\mathrm{n}=61)$ & 0.72 & .55 & 2.03 & .68 & 2.38 & .82 \\
Not Tested $(\mathrm{n}=124)$ & 0.60 & .52 & 1.93 & .70 & 2.10 & .77 \\
\hline
\end{tabular}

Note. $\underline{M}=$ Mean; $\underline{\mathrm{SD}}=$ Standard Deviation; $\mathrm{PR}=$ Perceived Risk.

ascale ranged from (0) "not at all" to (3) "extremely." 
risk levels for others of the same age. More than half of the respondents $(58 \%)$ indicated that others of the same age were "quite at risk," and $20 \%$ indicated that others were "extremely at risk." The differences between the two risk items were significant $(\mathrm{t}=-20.96, \mathrm{p}<.001)$ for the total sample. In addition, as shown in Table 7, respondents` own perceived risk was significantly correlated with testing intention $(\underline{r}=.28, \underline{p}<.001)$.

Despite the fact that the respondents reported a low perceived risk for HIV, the level of their concern about HIV and AIDS was high (see Table 6). It is noteworthy that the male subgroup reported less concern about HIV and AIDS than the female subgroup $(\underline{\mathrm{M}}=1.82$ for males and $\underline{\mathrm{M}}=2.39$ for females $)$. Coding gender as " 0 " for male and "l" for female, a significant correlation between gender and level of concern (Spearman's $\underline{r}=.32$ ) was obtained at .001 level of significance. Additionally, those who had previous testing experience reported higher concern $(\underline{M}=2.38)$ than those without testing experience $(\underline{M}=2.10)$. Coding test experience with " 0 " for no testing experience and " 1 " for presence of testing experience, a significant correlation between test experience and concern level (Spearman`s $\underline{r}=.20, \underline{p}<.01$ ) was found. As shown in Table 7 , the level of concern was correlated with testing intention $(\underline{r}=.30, \underline{p}<.001)$.

Relationship Between Demographic Variables and the TRA Variables

Analysis of variance (ANOVA) was performed to test the potential effects of demographic variables and HIV testing experience on the variables involved in 
Table 7

Pearson`s Correlations of Perceived Risk and Concern Variables with Other

$\underline{\text { Variables }}$

\begin{tabular}{llllll}
\hline \multicolumn{1}{c}{ Variables } & 1 & 2 & 3 & 4 & 5 \\
\hline 1. Perceived Risk & --- & & & \\
2. Concern about HIV & .11 & $-\ldots$ & & & \\
3. Attitude & -.09 & $.18^{*}$ & $-\ldots-$ & & \\
4. Subjective Norm & .08 & $.16^{*}$ & $.49 * * *$ &.-- & \\
5. Intention & $.28 * * *$ & $.30 * * *$ & $.35 * * *$ & $.63 * * *$ & --- \\
\hline Note. $* \mathrm{p}<.05 . * * \mathrm{p}<.01 . * * * \mathrm{p}<.001$. & & & & \\
\hline
\end{tabular}


the TRA. As a result, significant effects for respondents' previous testing experience were found with respect to testing intention, $\underline{E}(1,183)=28.42, \underline{p}<$ $.001:$ attitude. $\underline{F}(1,183)=7.40 . \underline{\mathrm{p}}<.01:$ and subjective norm, $\underline{F}(1,172)=23.90, \underline{\mathrm{p}}$ $<.001$. Mean scores of intention, attitude, and subjective norm in previously tested and not tested groups are listed in Table 2. Respondents who had previous testing experience indicated greater intentions to take an HIV test, more favorable attitudes towards HIV testing. and greater normative pressure (or subjective norm) than those without any testing experience.

Pertaining to current relationship status, significant results were found with respect to intentions, $\underline{F}(3,183)=9.50, \underline{p}<.001$ : attitudes, $\underline{F}(3,183)=6.46, \underline{p}<$ $.001 ;$ and subjective norms, $\underline{\mathrm{F}}(3.172)=5.15 . \mathrm{p}<.01$. Mean scores and standard deviations for the intention, attitude, and subjective norm variables with respect to relationship status are listed in Table 8. Tukey's Honestly Significant Difference (HSD) test revealed that those who were legally married had significantly $(\underline{p}<.01)$ lower intention scores than the other three groups. Likewise, the legally married respondents indicated significantly lower attitude scores than cohabiting respondents and single respondents without a partner $(\underline{p}<.05)$ and than single respondents with a partner but not cohabiting $(\mathrm{g}<.01)$. As for subjective norms, Tukey`s HSD indicated that those who were legally married had significantly lower subjective norm scores than single respondents with partners but not cohabiting. and than single respondents without a partner $(\underline{p}<.05)$. No other 
Table 8

Means and Standard Deviations of TRA Variables (with respect to relationship status)

\begin{tabular}{|c|c|c|c|c|c|c|}
\hline \multirow[t]{2}{*}{ Relationship Status } & \multicolumn{2}{|c|}{ Intention $^{\mathrm{a}}$} & \multicolumn{2}{|c|}{$\underline{\text { Attitude }}^{\mathrm{b}}$} & \multicolumn{2}{|c|}{$\underline{\text { Subjective Norm }}^{\mathrm{b}}$} \\
\hline & $\underline{M}$ & $\underline{S D}$ & $\underline{\mathrm{M}}$ & $\underline{\mathrm{SD}}$ & $\underline{\mathrm{M}}$ & $\underline{\mathrm{SD}}$ \\
\hline Legally Married $(n=35)$ & 2.80 & 1.81 & 68.89 & 30.95 & 29.29 & 28.26 \\
\hline Living Together as Married $(n=30)$ & 4.57 & 2.05 & 90.97 & 29.26 & 41.03 & 27.74 \\
\hline Single with Partner $(n=56)$ & 4.75 & 2.13 & 97.79 & 34.72 & 52.38 & 35.57 \\
\hline Single without Partner $(n=66)$ & 4.95 & 2.04 & 95.18 & 33.35 & 52.82 & 31.14 \\
\hline
\end{tabular}

Note. $\underline{M}=$ mean; $\underline{\mathrm{SD}}=$ Standard Deviation.

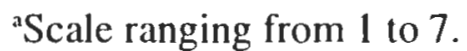

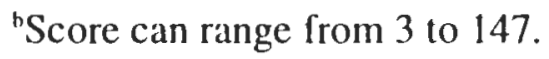


significant results were found with respect to age, gender, race, and sexual orientation for HIV testing intentions, attitudes, and subjective norms.

\section{HIV Testing Procedural Preferences}

Procedural preference questions had four elements to compare: (1) fluid sample taken (blood or saliva); (2) location of sampling (clinic/hospital or home); (3) preference to have counseling or not to have counseling before and after the testing, if they were HIV-negative, and if they were HIV-positive (yes or no); and (4) a means of receiving the test results (in face-to-face or by telephone). The second hypothesis stated that the characteristics of the new HIV tests would be chosen by more respondents than those of the conventional HIV tests. The results of the selections in percentage figures are presented in Table 9. As a whole, respondents in all subgroups preferred the characteristics of the conventional HIV testing more than those of the new HIV testing, except for the type of fluid sample that they preferred to be taken, and for counseling preference if they were HIVnegative. That is, more respondents chose clinic or hospital over home as the preferred location of sample taking. preferred to have counseling before and after the HIV tests, preferred to have counseling if they were HIV-positive, and chose "face-to-face" as the preferred means of receiving the test results over "by telephone." The chi-square test of independence was significant at the .001 significance level. For all the procedural elements, the percentages of the choices were relatively consistent across the subgroups (see Table 9). 
Table 9

\section{Percentages of Preference Selection}

\begin{tabular}{|c|c|c|c|c|c|}
\hline Preference Choice & $\begin{array}{c}\text { Total } \\
(\mathrm{N}=190)\end{array}$ & $\begin{array}{l}\text { Male } \\
(n=61)\end{array}$ & $\begin{array}{l}\text { Female } \\
(n=126)\end{array}$ & $\begin{array}{l}\text { Tested } \\
(n=61)\end{array}$ & $\begin{array}{l}\text { Not Tested } \\
\qquad(n=124)\end{array}$ \\
\hline \multicolumn{6}{|l|}{ Fluid } \\
\hline Blood & 48.4 & 54.1 & 46.0 & 44.3 & 51.6 \\
\hline Saliva & 51.6 & 45.9 & 54.0 & 55.7 & 48.4 \\
\hline \multicolumn{6}{|l|}{ Location } \\
\hline Clinic/Hospital & 68.8 & 71.2 & 69.4 & 71.7 & 68.9 \\
\hline Home & 31.2 & 28.8 & 30.6 & 28.3 & 31.1 \\
\hline \multicolumn{6}{|l|}{ Counseling Before Test } \\
\hline Prefer to have & 73.2 & 70.7 & 74.6 & 71.4 & 74.6 \\
\hline Prefer Not to have & 26.8 & 29.3 & 25.4 & 28.6 & 25.4 \\
\hline \multicolumn{6}{|l|}{ Counseling After Test } \\
\hline Prefer to have & 88.0 & 84.7 & 90.2 & 93.4 & 86.4 \\
\hline Prefer Not to have & 12.0 & 15.3 & 9.8 & 6.6 & 13.6 \\
\hline \multicolumn{6}{|l|}{ Counseling if Negative } \\
\hline Prefer to have & 37.9 & 29.5 & 42.1 & 39.3 & 37.1 \\
\hline Prefer Not to have & 62.1 & 70.5 & 57.9 & 60.7 & 62.9 \\
\hline \multicolumn{6}{|l|}{ Counseling if Positive } \\
\hline Prefer to have & 95.2 & 91.8 & 96.8 & 96.7 & 94.4 \\
\hline Prefer Not to have & 4.8 & 8.2 & 3.2 & 3.3 & 5.6 \\
\hline \multicolumn{6}{|l|}{ Receiving Result } \\
\hline Face-to-Face & 77.8 & 83.3 & 76.2 & 85.2 & 76.4 \\
\hline By Telephone & 22.2 & 16.7 & 23.8 & 14.8 & 23.6 \\
\hline
\end{tabular}

Note. All the numbers represent percentages. 
As for the fluid sample, blood and saliva were almost equally chosen by the total sample and all the other subgroups. As for their preferences to have counseling if they were HIV-negative. $62 \%$ of the respondents indicated that they would prefer not to have counseling. A test of independence indicated a significant mean difference between the two options (prefer or not to prefer) $\left(\chi^{2}=11.4, \mathrm{p}<\right.$ $.001)$

Other potential effects of variables involved in the present study on the procedural preferences were investigated by ANOVA's and correlation analyses. A significant relationship was found between the choice of the location and the level of intentions with $\underline{\mathrm{F}}(1,184)=4.30, \underline{\mathrm{p}}<.05$. Those who chose clinic or hospital as the preferred location had higher intention levels $(\underline{M}=4.59)$ than those who preferred home $(\underline{M}=3.88)$. Respondents' choices of having or not having counseling if they were HIV-positive was significantly related to their level of social concern about HIV and AIDS, $\underline{F}(1,185)=4.36, p<.05$. Those who preferred to have counseling in the HIV-positive situation indicated a higher level of social concern $(\underline{M}=2.23)$ than those who preferred not to have counseling $(\underline{M}=$ 1.67). Significant relationships were also found between respondents' preferences of whether or not to have counseling if they were HIV-negative. and (1) their level of social concern, $\underline{F}(1,186)=10.85, \underline{p}<.01$ and $(2)$ their level of testing intention, $\underline{F}(1.188)=6.81 . \underline{\mathrm{p}}<.01$. Those who would not want counseling after their 
notification of an HIV-negative result had lower levels of social concern about HIV and $\operatorname{AIDS}(\underline{\mathrm{M}}=2.06)$ than those who wanted counseling in the situation $(\underline{\mathrm{M}}=$ 2.44). (Spearman"s $\underline{r}=-.22, \underline{p}<.01$, "0" for "yes" and "1" for "no" were assigned for preference coding). Similarly, those respondents who preferred not to have counseling in the HIV-negative situation had lower intention scores $(\underline{\mathrm{M}}=4.08)$ than those who preferred counseling $(\underline{M}=4.92)$.

\section{HIV Testing Intentions When HIV Tests Offer Procedural Options}

The third hypothesis predicted that respondents' intentions to take an HIV test that incorporated their procedural preferences would be higher than their intentions to take an HIV test in general. Responses to the measure of intentions to take an HIV test that incorporated their preferences had a mean score of 5.56 and a standard deviation of 1.7 for the total sample. The mean score of this measure was higher than that of intention $\mathrm{A}(\underline{\mathrm{M}}=4.40$. and $\underline{\mathrm{SD}}=2.1)$. Student's paired $\underline{\mathrm{t}}-\mathrm{test}$ was used to test the third hypothesis. The mean difference from intention $\mathrm{A}$ was significant, $\underline{\mathrm{t}}(189)=9.50, \mathrm{p}<.001$, two-tailed, for the total sample, and was significant across the subgroups (see Table 10). Respondents of all the subgroups had significantly higher intention scores for HIV tests that had their preferred procedural conditions than they did for their general HIV tests. 
Table 10

T-scores between General Intentions to Take an HIV Test and Intentions to Take a Test with Preferred Methodological Conditions

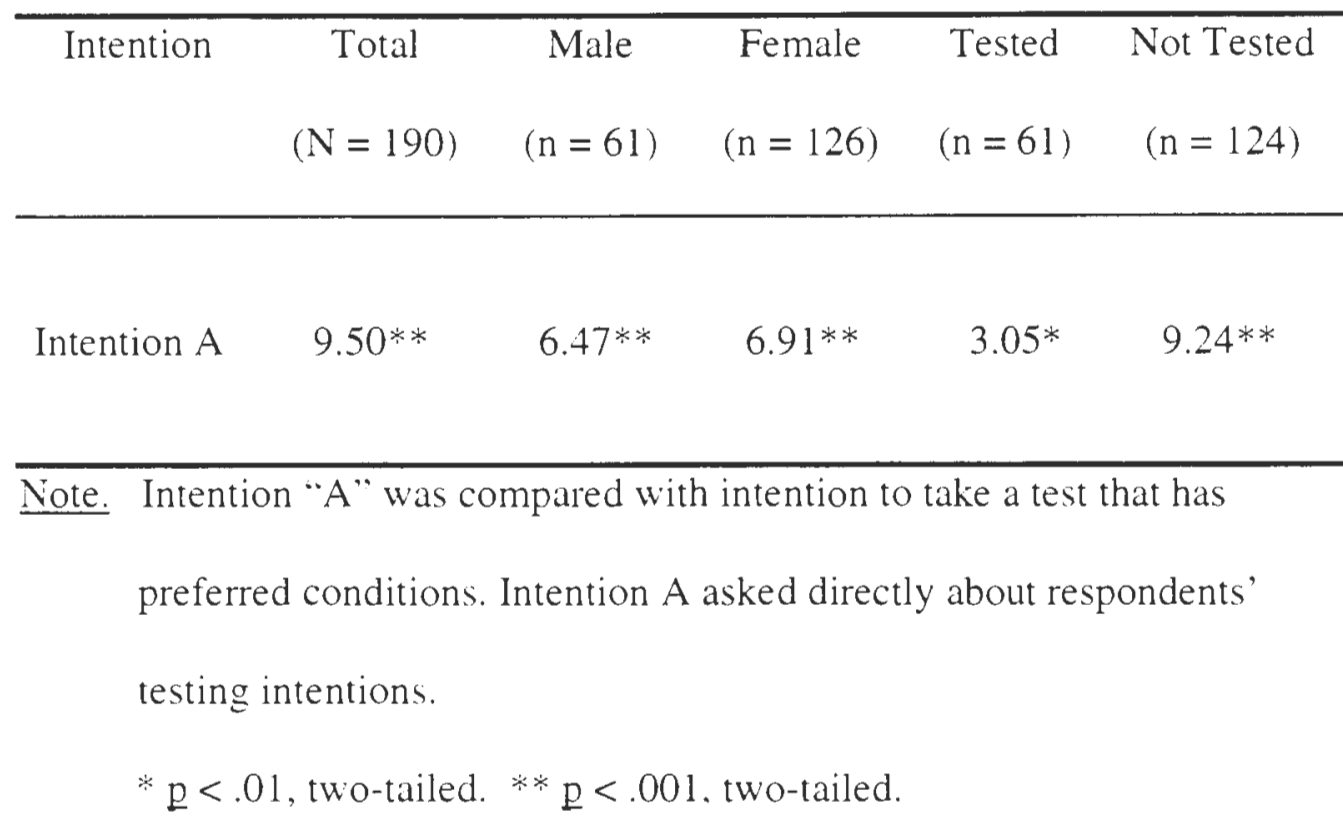




\section{Discussion}

The first goal of the present study was to investigate the utility of the Theory of Reasoned Action (TRA) in predicting HIV testing intentions in college students. The TRA is a useful framework for examining the role of attitudes toward HIV testing and perceptions of social pressure toward HIV tests on testing intentions. The results of the multiple linear regression analysis provided partial support for the first hypothesis that predicted that respondents' attitudes and subjective norms would determine testing intentions. Overall, $41 \%$ of the variance in testing intentions was accounted for by attitudes and subjective norms. However, the predictive power was almost entirely driven by subjective norms, while the attitude component failed to predict testing intentions.

\section{Effects of Subjective Norms on Testing Intentions}

As expected, the subjective norm component significantly predicted HIV testing intentions. That is, those who perceived social pressure from referents (friends, sexual or dating partners, and parents) with whom they generally comply, indicated greater intentions to test for HIV. Conversely, respondents with lower subjective norm scores were less likely to indicate that they would be tested. Although past research (Cochran et al., 1992, for example) discounted the effects of subjective norms on HIV preventive intentions, the present study supported the subjective norm-intention relationship of the TRA in HIV testing.

Similar to the studies of Meadows et al. (1993) and Lupton et al. (1995) on 
the motives for taking HIV tests. the present study found that influences from sexual or dating partners were substantial. Lupton et al. argued that heterosexual college students were motivated to undergo testing for HIV when they were exhorted by others, especially their sexual partners, and when they wanted to show a proof of cleanliness to their dating or sexual partners. Lupton et al. also found that males were more likely to be influenced by females in deciding to take an HIV test. A similar result was observed in the present study. As shown in Table 5. which presents the results of bivariate regression analyses, the regression coefficient by partner referent measure of the subjective norm on testing intentions was the highest, and was extremely high in the male group. This suggests that the social influence of others is most important for HIV testing, especially in males. The present study also found that not only partners, but also friends and parents. could strongly influence testing intentions.

\section{Effects of the Attitude on Testing Intention}

Unlike the previous research on HIV preventive intentions in which the attitude components were reported to be the major predictor of preventive intentions (Cochran et al., 1992: Fisher et al.. 1995: Krahe \& Reiss, 1995), the attitude measures composed of the evaluations of testing behaviors did not predict testing intentions as well as the subjective norm measures in the present study. There are two potential reasons for this. First. the attitude measures may have lacked validity. Although the attitude items possessed face validity. they may have 
been too broad in scope. For example, the attitude question in the health status confirmation (HSC) context asked if taking an HIV test to make sure of one's health status is good or bad. The HSC's weak predictive power is shown in Table 5. While the question was constructed based on the standard practice for measuring the attitude component in the Theory of Reasoned Action, it may not have been specific enough for respondents to assess whether taking an HIV test really was a good indication of their health status. A similar explanation may be appropriate for the measure of future health behavior, asking if taking an HIV test to guide their future health behavior is good or bad. HIV testing may not be perceived as ordinary health examinations like blood pressure tests, cholesterol tests. and cancer screenings either because people do not perceive HIV as a threat to their health or because they have too many fears about HIV testing. This could lead these questions to be meaningless in the context of HIV testing intentions. Thus, asking respondents` favorability toward HIV testing like other health examinations may not be able to obtain valid responses. However, the attitude measure on relationship context, asking if taking HIV tests to establish or secure their relationships with their dating or sexual partner is good or bad, was a good predictor of testing intentions (see Table 5).

Secondly, assuming the validity of the attitudinal components, the attitude measures in terms of what taking an HIV test would bring to respondents ${ }^{*}$ own health status or health behaviors may not be a good predictor of testing intentions. 
With respect to the subjective norm measures, individuals may respond more to the motivational pressures from important others and what the testing would bring to their relationships with other people close to them, particularly their dating or sexual partners, rather than what the testing would bring to their health behaviors. This interpretation may explain the ineffectiveness of health confirmation and future health behavior contexts and the effectiveness of relationship context of attitudinal measures in predicting testing intentions.

Arguments may exist as to why past studies on HIV preventive for safer sex behaviors obtained results which emphasized the effects of attitudes and not the subjective norm components. The present study on HIV testing intentions emphasized results that were completely opposite. The difference between the two kinds of studies may be the levels of individuals' emotional impacts with respect to preventing the HIV infections and taking an HIV test. While individuals may not strongly perceive the possibility of HIV infections in deciding to practice safe sex, the emotional impact. including fears and worries, is assumed to be very strong in deciding to test for HIV since those who test for HIV may be faced with a life threatening disease and the possible realization that they may have infected others. What is common among most of the HIV test takers is the fact that they have fears of testing and the results, along with a sense of social responsibility in which they feel the need to be tested for the sake of others, even though they may have practiced prevention and may perceive low personal risks for HIV. Thus, the 
Intention to take HIV tests 64

immediate fears and worries may overpower their low personal risks, their confidence of not having HIV, and their sense of favorability or infavorability toward HIV testing. Past studies on HIV testing motivations emphasized that social effects were the major motivators to test for HIV, i.e., whether individuals intended to test for HIV when others asked them or to obtain a reassurance that they were HIV-negative. In other words, social responsibility may be a motivational factor in deciding to test for HIV. The present study found similar results on the effects of social norms.

The potential inability of attitudes to predict HIV testing intentions could also be explained by the direct measure of attitude, which asked, "What is your attitude toward your taking an HIV test?" The bivariate regression coefficient of the direct attitude measure on testing intention was .34 , which was very similar to that of computed attitude measures on testing intentions $(\underline{R}=.35)$. Additionally, in multiple regression analysis with a direct attitude measure and a computed subjective norm measure as the predictors of testing intentions, the attitudinal weight was not significant $(\beta=.12, p>.05)$. Thus, the effect of the direct attitude measure to intentions was very similar to the effects of computed attitude measures. Assuming the direct attitude measure was valid, the inefficacy of the attitudinal component of the TRA in HIV testing context could be suggested. Considering these possibilities. one might be able to speculate that 
attitudinal influence in predicting HIV testing intentions (except individuals' favorability toward testing in a relationship context) was not as strong as the subjective norms and as it was in previous HIV prevention studies. However, the role of attitudes in HIV testing intentions cannot be conclusively supported on the basis of the present data.

Demographic Differences on HIV Testing Intentions

Respondents who have previous HIV testing experience indicated greater favorability toward HIV testing (or attitudes), perceptions of social pressures (or subjective norms), and intentions to test for HIV infections than those who have not been tested for HIV. This result indirectly supported the effectiveness of the TRA in the efficacy of the intention-behavior model. However, since it is impossible to figure out whether the tested respondents had held the intentions to test for HIV prior to their testing, the intention-behavior link is inconclusive in this study.

The strong social influence on college students' testing intentions was discussed previously. However, respondents' relationship status revealed a significant result indicating an exception of the subjective norm influence for those who were legally married. Married respondents showed lower subjective norm scores than those of single respondents whether or not the single respondents were with a partner. Therefore. it can be assumed either that married students were not influenced by social pressures regarding HIV testing decisions or that students 
no longer perceive any chance of infection as soon as they get married (presumably because they perceive that they are committed to a monogamous relationship). Not only the subjective norm scores, but also the scores for attitudes and testing intentions for married respondents were significantly lower than for single respondents. Thus, it appears the state of being married provided the perception that they were shielded from the possibility of HIV infection and provided them with little felt need for testing.

No major differences on the TRA variables were found with respect to respondents" age or gender. Unfortunately, proposed comparisons among various sextaal orientations and among various races on the TRA variables were not possible because of the low numbers of homosexual and bisexual students and from students of racial minorities in this study.

\section{$\underline{\text { HIV Testing Procedural Preferences }}$}

The second goal of the present study was to investigate whether college students favored newly emerged HIV tests over the conventional HIV tests by examining their preferences in testing procedures. The 1992 National Health Interview Survey (NHIS) cited by Phillips et al. (1995) and Freundlich and Hamilton (1996) showed that many people favored the home HIV tests. However. the results of the present study indicated that college students generally favored the characteristics of the conventional HIV tests.

The second hypothesis was not supported for all the procedural categories 
except a counseling preference item. The majority of the respondents (62\% of the total sample. $71 \%$ of the male and $58 \%$ of the female subgroups) preferred not to have the post-test counseling after HIV-negative results. Responses from the openended questions reported such counseling would not be necessary in the situation although they valued the necessity of the counseling if they should received an HIV-positive result. Although this result was not directly related to the distinction of conventional and new HIV tests because post-test counseling in home tests is provided and expected to be taken on the phone, a lot of people are expected to ignore the phone messages that are equivalent to the post-test counseling of conventional tests. If test takers should choose the home tests based on their preferences on this element and ignore the phone messages, they would not be instructed about important aspects of HIV testing and their results including the facts about window periods and seroconversions. Inattention to information after a negative result may put other future partners at risk because of the time it takes to have the HIV antibody produced in the blood stream. This inattention is a very critical issue that must be dealt with carefully by the government and the test producers. Further studies are necessary to understand these issues in detail so that the new HIV tests are properly and effectively employed.

As a whole, the results of the present study implied that the respondents who indicated their preferences for the characteristics of the new HIV tests had lower level of testing intentions and social concerns about HIV and AIDS. For 
example, respondents who chose home as the preferred location for the testing were more likely to indicate lower intentions to take an HIV test than those who preferred clinic or hospitals as the testing site. Those who preferred not to have counseling after an HIV-negative result had fewer concerns about HIV and AIDS as a social problem and lower intention levels than those who preferred to have counseling in the situation.

The new HIV tests were so controversial because of the attempt to convert the face-to-face methods to a more private method similar to home pregnancy tests. However, the majority of the respondents in this study indicated a reluctance toward the new home HIV tests, reporting that they valued the importance of the professional involvement in testing.

Saliva testing is a new method developed to ease the testing by eliminating the physical pain and fear associated with blood draws and to make the testing simpler for clinic staffs. Unlike the other procedural categories in which preferences were relatively single-sided, the preferences for the sample fluid element were split equally (see Table 9). In the total sample, and in all of the subgroups, blood and saliva were equally chosen as the preferred body fluid to be taken for HIV tests. Some respondents who favored saliva emphasized the benefit of not having the pain. A few of them mentioned their strong fear of needles. On the other hand, some respondents who favored blood mentioned that they were not convinced of the accuracy of the saliva tests. Thus, giving the test takers some 
options for fluid samples instead of limiting testing to one type of fluid sample may be beneficial for test takers.

The third hypothesis that predicted an increase in respondents' testing intentions after they were given the methodological options in HIV testing procedures was supported. Respondents indicated significantly greater intentions to take an HIV test that incorporated their procedural preferences than their general intentions to test for HIV. The increase in intention levels was observed in all the subgroups and shown in terms of t-scores in Table 10. Therefore, the reasons that many college students have not taken HIV tests could lie in testing procedures. Future studies are necessary to investigate further which methodological factors lead to an increase in testing intentions.

\section{Practical Contributions from the Present Study}

The present study obtained results that may help HIV testing programs and HIV educators improve their approaches to guide people, college students in this case, to effectively and appropriately decide to test for HIV.

\section{Effects of Social Influence. Unlike the studies on HIV preventive} behavioral intentions, the present study found that social norms rather than attitudes were more predictive of college students' testing intentions. Therefore, there is a need to have separate approaches in educating students; one in an effort to guide them to practice HIV preventive behaviors and the other to educate them on HIV testing in general. including when to test for HIV and how to ask others to 
take an HIV test. In other words. HIV education needs to involve discussions about social influences related to HIV testing. It may be valuable to teach students some communication strategies so that they would not face difficulties when they need to ask others about testing for HIV. This HIV education can be applied in a number of situations including classes at schools or colleges, the media, and so forth. Similarly, HIV testing institutions could take advantage of the importance of social influences in their testing programs. They could, for example, provide programs that teach individuals effective ways to communicate with their sexual partners in asking them to undergo HIV testing or in asking their partner whether they could take the test together. Although providing such programs may not be feasible for some testing facilities, HIV counselors must be educated about those issues so that they can effectively advise test takers with such concerns.

Perceived Risk and HIV Concerns. The present study found that respondents' concerns about HIV and AIDS as social problems were positively related to their testing intentions, meaning that the more concerned about HIV and AIDS they were, the more likely they intended to take HIV tests. Likewise, their own risk perception was found to be positively correlated with their testing intentions. Thus, those who perceived higher personal risks to HIV had greater intentions to take HIV tests, while those who had lower perceived risk were less likely to intend to test for HIV infections. The concern about HIV and risk perception can be assumed to be influenced by HIV education in various forms. 
Intention to take HIV tests 71

Overall. the respondents indicated a high level of concern about HIV and AIDS, which implied the effectiveness of HIV education. As shown in Table 6. however. male respondents indicated lower levels of concern than female respondents. This imbalance may become a barrier in facilitating partner communications. It would appear that HIV education needs to increase the concerns about HIV issues in male students.

On the other hand. HIV education did not appear to have increased respondents sense of vulnerability to HIV. Respondents indicated that their risks were much lower than those of others of the same age. If their low perceived risk resulted from their perfect prevention from HIV, there would not be any problems. However, if low risk was the result of denial or misinformation. HIV educators need to correct their misperceptions. More importantly, during the course of life, anyone may face the need to test for HIV. When the time comes. people may be able to deal effectively with themselves and possibly with their partners if they have the skills of proper risk assessment. Thus, HIV education must teach students how to assess their risks for HIV infections.

HIV Testing. The present study found the effectiveness of providing procedural options to HIV tests. Respondents had their own preferences for HIV tests such as fluid samples, means of receiving results, and location of the testing. Even more appealing was that they indicated greater intentions to take the test which incorporated their preferences. 
Additionally, the majority of the respondents reported that they valued the professional involvement in HIV testing, therefore, supporting the characteristics of the conventional HIV tests. However, if college students should decide to take home HIV tests, tremendous caution must be taken. This study found that those who preferred the characteristics of the new HIV tests (especially home tests) had less concern about HIV and AIDS. If individuals decide to take home tests, there would be a great concern about whether or not they would benefit in spite of the lack of a professional involvement.

The development of the home HIV tests has been controversial in many other respects. Arguments exist concerning the possible misuse or abuse of the home tests. For example. the authorities are afraid that people might directly or indirectly force others to take the tests since they are easily available and used. In addition. the impact of the notification of the positive results on telephone could be beyond the common imagination, leading the tested to be out of control and some possibly to commit suicides. Although the oppositions to the home HIV tests were expressed in words by many respondents of this study, mainly regarding the lack of professional involvement in the home testing, it was true that some respondents strongly favored the characteristics of the home tests. Therefore, the governmental authorities and HIV education must be careful in evaluating the home testing. and at the same time, people in general must be educated in advance about the HIV testing procedures and what the possible results mean. 


\section{$\underline{\text { Limitations and Possible Solutions }}$}

The limitations of the present study cannot be ignored. Four potential problems and their possible solutions were recognized. First. although the sample size was large enough for statistical analyses, it may have been too small to draw conclusions as definitively as desired. Additionally, all of the demographic categories were unbalanced. For example, roughly two-thirds of the total sample was female. The worst cases were recognized in the variables of race or ethnicity and sexual orientation. The great majority of the respondents were white heterosexuals making proposed comparisons among different racial groups and among individuals with different sexual orientations impossible. Considering the student population of the particular university in which white heterosexual students are the majority, the disproportionate groups for sexual orientations and racial groups can be understood. However, different approaches in data collection may be necessary to make demographic comparisons. Future studies should employ data collection methods that target diverse groups so that such comparisons can be made.

Secondly, there is a lack of generalizability in the present study. Externalizing the present results to a national college student population is not appropriate partly because the present study collected data from one particular university in a northwest part of the United States and because the sample size was small. The geographical difference may signify many differences in various 
aspects such as political climate, efforts of HIV education and HIV testing. and people's attitudes toward HIV issues. Therefore, it would be preferable for future studies to focus on obtaining data from as many individuals and in as many locations as possible.

Third, as mentioned, since established measures of attitudes and subjective norms in HIV testing contexts were not available, they were constructed using the guidelines of Ajzen and Fishbein (1980). The validity of the present measures need further studies to be evidenced. In addition, intention measures may also present a limit to this study. There were only two questions inquiring about respondents' intentions to test for HIV. One of them (named intention B) was thrown out of the analyses because the responses to the question were not strongly predicted by the antecedents and because it did not clearly ask about respondents' testing intentions. The intention question that was used in the analyses (named intention A) directly asked about the respondents' intentions, and therefore, was assumed by the researcher to be an appropriate intention measure for this study. Future studies may want to explore the intention questions further.

Finally, the attitudes, subjective norms, and testing intentions were measured based on the respondents" self reports. Although survey questionnaires are the standard practice in HIV-related studies, there may be some factors that distort their real thoughts and influence the data. For example, social desirability may be affecting the expression of attitudes, subjective norms. and intentions. The 
desire to appear socially favorable may be active especially in those who had a great amount of HIV education. Unfortunately, there is no other way to collect data on these TRA variables. Thus, in the hopes for reducing social desirability, the present study enforced a strict anonymity in the survey process and informed the respondents of it.

\section{Suggestions for Future Research}

Since the present study was exploratory in many respects, there were many aspects that need further study in order to reveal more detailed explanations and to contribute to the understanding of HIV testing and education. First of all, the motivational aspect of HIV testing intentions must be investigated. In this study, social effects were emphasized. However, research has yet to examine how social normative beliefs influence individuals' HIV testing intentions. Future studies may identify some factors that can be integrated into the TRA model to improve its predictability. Future studies may also explore why respondents of this study were strongly influenced by their friends and parents as well as their sexual or dating partners with respect to testing intentions.

Attitudinal component of the TRA in HIV testing contexts need further studies to improve the interpretations of the present results. Question constructions of attitude component in HIV testing contexts must be studied so that attitudinal measures can improve its validity. Besides the validity issues, a further issue here may be determining an effective application of attitudinal contexts. In the present 
Intention to take HIV tests 76

study, respondents' attitudes were asked in terms of their evaluations of what taking an HIV test brings to their health behaviors and to their relationships with sexual or dating partners. Although the relationship context was satisfactory in determining testing intentions, the other measures in health contexts did not sufficiently predict intentions. Future studies may profit from an in-depth examination of the contextual pictures in attitudinal component of the TRA model.

Secondly, the present study only examined the utility of the TRA model in accounting for respondents ' HIV testing intentions. Future research is necessary to demonstrate whether it can predict college students' subsequent HIV testing behaviors. A longitudinal study may be able to evaluate the intention-behavior link of the TRA in HIV testing contexts. The challenge is to examine the relationship between intentions to obtain an HIV test and actually getting tested. Understanding the motivation for obtaining testing will lead to more effective education strategies.

Finally, further studies are necessary to investigate the efficacy of the coming HIV tests. Since the trend of HIV testing is to become more convenient, it is expected that more privately-oriented HIV tests than the ones already available are going to be produced and approved for easy use. Future studies need to help government authorities evaluate the utility of the proposed HIV tests and suggest potential positive and negative aspects. Although it may be important to provide various testing opportunities for those who would not otherwise take the 
conventional HIV tests, careful consideration of the various components of testing is necessary before implementing various changes in testing procedures.

Nonetheless, the current study presented an important step in developing a model of HIV testing intentions. Empirical studies that investigate influential factors which affect individuals' intentions to test for HIV infections may improve the approaches taken by HIV testing programs and HIV education in general, which may in turn assist the fight against AIDS. In summary, one clear-cut finding obtained by the present study was the overwhelming impact of social norms in predicting HIV testing intentions among college students. This result indicated that HIV testing intentions were different from HIV preventive intentions in terms of predictive powers of attitude and subjective norm components, suggesting that differential approaches are necessary in the interventions of HIV prevention and testing. 


\section{References}

Ajzen. I. (1971). Attitudinal vs. normative messages: An investigation of the differential effects of persuasive communication on behavior. Sociometry, 34. $263-280$.

Ajzen. I. (1988). Attitudes, personality, and behavior. Chicago: The Dorsey Press.

Ajzen. I. \& Fishbein, M. (1977). Attitude-behaviour relations: A theoretical analysis and review of empirical research. Psychological Bulletin. 84. $888-919$

Ajzen, I. \& Fishbein, M. (1980). Understanding attitudes and predicting social behavior. New Jersey: Prentice-Hall. Inc.

Bandura. A. (1977a). Social Learning Theory. Englewood Cliffs, NJ: Prentice-Hall.

Bandura. A. (1977b). Self-efficacy: Toward a unifying theory of behavioral change. Psychological Review, 84, 191 - 215.

Basch. C. (1989). Preventing AIDS through education: Concepts, strategies, and research priorities. Journal of School Health, 59, 296 - 299.

Bayer, R., Stryker, J., \& Smith. M. D. (1995). Testing for HIV infection at home. The New England Journal of Medicine. 332. 1296 - 1299.

Bruce. K. E., Pilgrim. C. A., \& Spivey, R. L. (1994). Assessing the impact of Magic Johnson's HIV positive announcement on a university campus. Journal 
of Sex Education and Therapy, 20, 264 - 276.

Centers for Disease Control and Prevention. (1995). U.S. HIV and AIDS cases reported through December, 1994. HIV/AIDS Surveillance Report, 6, 5.

Chilman. C. S. (1983). Adolescent sexuality in a changing American society: Psychological perspectives for the human service professions. New York: Wiley Interscience.

Chu. S.. Buehler. J., \& Berkelman. R. (1990). Impact of the human immunodeficiency virus epidemic on mortality of women of reproduction age, United States. Journal of American Medical Association, 264. 225 - 229.

Cochran. S. D., Mays, V. M., Ciarletta, J., Caruso, C., \& Mallon, D. (1992). Efficacy of the Theory of Reasoned Action in predicting AIDS-related sexual risk reduction among gay men. Journal of Applied Social Psychology. 22. $1481-1501$.

Dawson. J.. Fitzpatrick. R., McLean, J., Hart. G., \& Boulton, M. (1991). The HIV test and sexual behavior in a sample of homosexually active men. $\underline{\text { Social }}$ Science and Medicine, 32, $683-688$.

Feldman. J. (1966). The dissemination of health information. Chicago: Aldine.

Fishbein. M. (1967). Readings in attitude theory and measurement. New York: Wiley.

Fishbein. M. \& Ajzen, I. (1975). Belief, attitude intention and behavior. 
An introduction to theory and research. Massachusetts: Addison-Wesley Publishing Company.

Fisher, W. A., Fisher, J. D.. \& Rye, B. J. (1995). Understanding and promoting AIDS-preventive behavior: Insights from the Theory of Reasoned Action. Health Psychology, 14. 255 - 264.

Freundlich, N. \& Hamilton, J. (1996). The trials of a home HIV test. Business Week. March 18. 56 - 58.

Gale Research Inc. (1995). Gale country and world rankings reporter. Detroit. MI: Gale Research Inc.

Gallois. C., Kashima, Y., Terry, D., McCamish, M., Timmins, P., \& Chauvin, A. (1992). Safe and unsafe sexual intentions and behavior: The effects of norms and attitudes. Journal of Applied Social Psychology, 22, $1521-1545$.

Glanz. K.. Lewis, F. M., \& Rimer, B. K. (1990). Health behavior and health education. San Francisco: Josseys Bass, Inc.

Haefner, D., Kegeles, S., Kirscht. J., \& Rosenstock, I. (1967). Preventive actions in dental disease, tuberculosis and cancer. Public Health Reports, 82. 187 $-200$.

Hardy. A. M. \& Dawson, D. A. (1990). HIV antibody testing among adults in the United States: Data from 1988 NHIS. American Journal of Public Health. $\underline{80 .} 586-589$.

Hobfoll. S. E.. Jackson. A. P.. Lavin. J.. Britton, P. J., \& Shepherd. J. B. 
(1993). Safer sex knowledge, behavior, and attitudes of inner-city women. Health Psychology. 12, $481-488$.

Holmes, K., Karon, J., \& Kreiss, J. (1990). The increasing frequency of heterosexually acquired AIDS in the United States. 1983-88. American Journal of Public Health, 80, $858-862$.

Jacobson, P. B., Perry, S. W., \& Hirsch, D. (1990). Behavioral and psychological responses to HIV antibody testing. Journal of Consulting and Clinical Psychology, 58, 31 - 37.

Janz. N. K. \& Becker. M. H. (1984). The Health Belief Model: A decade later. Health Education Quarterly, 11. 1 - 47.

Kalichman. S. C., Hunter. T. L., \& Kelly, J. A. (1992). Perceptions of AIDS susceptibility among minority and non-minority women at risk for HIV infection. Journal of Consulting and Clinical Psychology, 60. 725 - 732.

Kelly, J., Kalichman. S., \& Kauth, M. (1991). Situational factors associated with AIDS risk behavior lapses and coping strategies used by gay men who successfully avoid lapses. American Journal of Public Health, 81, 1335 1338.

Kirscht, J. P. (1983). Preventive health behavior: A review of research and issues. Health Psychology. 2. 277 - 301.

Krahe. B. \& Reiss. C. (1995). Predicting intentions of AIDS-preventive behavior among adolescents. Journal of Applied Social Psychology, 25, 2118 - 
$21+0$.

Lairson. D. \& Swint. J. (1978). A multivariate analysis of the likelihood and volume of preventive demand in a prepaid group practice. Medical Care, 16. $730-739$.

Leary. W. E. (1994). Government panel hears call for expanded AIDS testing. New York Times, June 23.

Leukefeld. C. G. \& Haverkos, H. W. (1993). Sexually transmitted diseases. In T. P. Gullotta. G. R. Adams, \& R. Montemayor (Eds.), Adolescent sexuality (161-180). Newbury Park, CA: Sage.

Lewis, V. J. \& Kashima, Y. (1993). Applying the Theory of Reasoned Action to the prediction of AIDS-preventive behavior. In D. Terry. C. Gallois, \& M. McCamish (Eds.) The theory of reasoned action: Its application to AIDSpreventive behavior. (29-40). Oxford, England: Pergamon Press Inc.

Lierman, L. M., Young, H. M., Kasprzyk. D., \& Benoliel, J. Q. (1990). Predicting breast self-examination using the Theory of Reasoned Action. Nursing $\underline{\text { Research, 39, } 97-101 .}$

Lupton. D., McCarthy, S., \& Chapman, S. (1995). 'Doing the right thing': The symbolic meanings and experiences of having an HIV antibody test. Social Science and Medicine, 41, $173-180$.

Lyter, D. W., Valdiserri, R. O., Kingsley. L. A., Amoroso, W. P., \& Rinaldo, C. R. (1987). The HIV antibody test: Why gay and bisexual men want or 
do not want to know their results. Public Health Reports, 102. 468 - 474.

Mandler. G. (1967). Verbal learning. In T. M. Newcomb (Ed.), New directions in psychology, (1 - 50). New York: Holt.

Manning, T. D., Barenberg, N., Gallese, L., \& Rice, J. C. (1989). College students' knowledge and health beliefs about AIDS: Implications for education and prevention. Journal of American College Health. 37, 254 - 259.

Marwick, C. (1995). Home testing kits for HIV apt to get FDA approval. The Journal of American Medical Association, 273, 908 - 909.

McCusker, J., Stoddard, A. M., Mayer, K. H., Zapka, J., Morrison. C., \& Saltzman. S. P. (1988). Effects of HIV antibody test knowledge on subsequent sexual behaviors in a cohort of homosexually active men. American Journal of Public Health, 78, $462-467$.

Meadows. J., Catalan, J., \& Gazzard, B. (1993). I plan to have the HIV test: Predictors of testing intention in women attending a London antenatal clinic. AIDS Care. 5. $141-148$.

Merson. M. H. (1992). Longitudinal trends in the epidemic. National AIDS Bulletin. September. $28-30$.

Miller, G. A. (1956). The magical number seven: Plus or minus two: Some limits on our capacity for processing information. Psychological Review, 63. 81 97.

Modeste. N. N.. Francis, C.. \& Matshazi, D. (1994). AIDS-related 
Intention to take HIV tests 84

knowledge, attitudes, beliefs, and behavioral intentions of adolescents in Trinidad: A pilot study. International Quarterly of Community Health Education. 14, 273 281.

Montano, D. E. (1986). Predicting and understanding influenza vaccination behavior: Alternatives to the health belief model. Medical Care, 24, $438-453$.

Morrison. D. M.. Baker. S. A., \& Gillmore, M. R. (1994). Sexual risk behavior, knowledge, and condom use among adolescents in juvenile detention. Journal of Youth and Adolescence, 23, $271-288$.

Myers, T., Orr, K. W., Locker, D., \& Jackson, E. A. (1993). Factors affecting gay and bisexual men's decisions and intentions to seek HIV testing. American Journal of Public Health. 83, $701-704$.

Nathanson, C. (1977). Sex, illness, and medical care: A review of data. theory, and method. Social Science and Medicine. 11, 13 - 25.

Osgood. C. E., Suci. G. J.. \& Tannenbaum. P. H. (1957). The measurement of meaning. Urbana. IL: University of Illinois Press.

Petosa, R. \& Wessinger, J. (1990). Using the health belief model to assess the HIV education needs of junior and senior high school students. International Quarterly of Communication Health Education, 10, 135 - 143.

Phillips, K. A., Flatt, S. J., Morrison, K. R., \& Coates, T. J. (1995). Potential use of home HIV testing. The New England Journal of Medicine. 332. $1308-1310$. 
Price, J. H.. Desmond, S., \& Kukulka, G. (1985). High school students` perceptions and misperceptions of AIDS. Journal of School Health, 55, 107 - 109.

Quin, T. C., Narain, J. P., \& Zacarias, F. R. K. (1990). AIDS in the Americas: A public health priority for the region. AIDS, 4, $709-724$.

Seigel. K., Levine, M. P., Brooks, C., \& Kern, R. (1989). The motives of gay men for taking or not taking the HIV antibody test. Social Problems, 36. 368 383.

Selik. R. M., Castro. K. G., \& Pappaioanou, M. (1988). Racial/ethnic differences in the risk of AIDS in the United States. American Journal of Public Health. 78, $1539-1545$.

Sheppard, B. H.. Hartwick. J.. \& Warshaw, P. R. (1988). A theory of reasoned action: A meta-analysis of past research with recommendations for modifications and future research. Journal of Consumer Research, 15. 325 - 343.

Smetana, J. G. \& Adler, N. E. (1980). Fishbein's value X expectancy model: An examination of some assumptions. Personality and Social Psychology Bulletin. 6, $89-96$.

Snyder, J. J. (1989). Health psychology and behavioral medicine. New Jersey: Prentice-Hall.

Steffen, V. J. (1990). Men's motivation to perform the testicle self-exam: Effects of prior knowledge and educational brochure. Journal of Applied Social Psychology, 20. $681-702$. 
Strunin. L. (1991). Adolescents` perceptions of risk for HIV infection: Implications for future research. Social Science and Medicine, 32, 221 - 228. Terry, D.. Gallois, C., \& McCamish. M. (1993). The theory of reasoned action and health care behavior. In D. Terry, C. Gallois, \& M. McCamish (Eds.), The theory of reasoned action: Its application to AIDS-preventive behavior (1 28). Oxford, England: Pergamon Press.

Theodorakis. Y. (1994). Planned behavior, attitude strength, role identity, and the prediction of exercise behavior. The Sport Psychologist, 8, $149-165$.

Thurman. Q. C. \& Franklin, K. M. (1990). AIDS and college health: Knowledge. threat. and prevention at a northeastern university. Journal of American College Health. 38. $179-184$.

U.S. Bureau of the Census. (1995). Statistical abstract of the United States 1995 (115 $5^{\text {th }}$ Edition). Washington D.C.

van Griensven. G. J. P., de Vroome, E. M. M., \& Teilman, R. A. P. (1988). Impact of HIV antibody testing on changes in sexual behavior among homosexual men in The Netherlands. American Journal of Public Health, 78, $1575-1577$.

Vargo, M. E. (1992). The HIV test: What you need to know to make an informed decision. New York: Pocket Books.

Woodworth, R. S. \& Schlosberg. H. (1954). Experimental psychology. New York: Holt. 


\section{Appendix}

Questionnaires 


\section{Questionnaire- instructions are omitted}

1. How certain are you that taking an HIV test is an effective way to make sure of your health status?

$\begin{array}{ccccccc}1 & 2 & 3 & 4 & 5 & 6 & \begin{array}{c}7 \\ \text { Definitely } \\ \text { Uncertain }\end{array} \\ \text { Certain }\end{array}$

2. How certain are you that taking an HIV test is an effective way to establish or secure your relationships with dating or sexual partners (or your future partners)?
Definitely
$\begin{array}{llllll}2 & 3 & 4 & 5 & 6 & 7\end{array}$
Uncertain
Definitely
Certain

3. How certain are you that taking an HIV test is an effective way to guide your future heath?

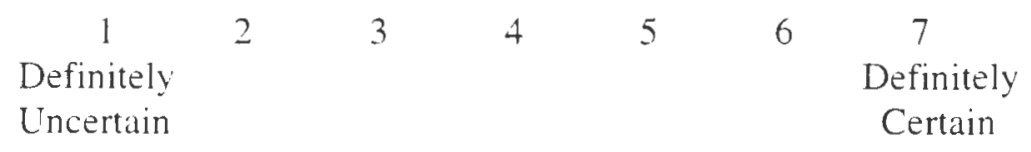

4. What is your attitude toward your taking an HIV test?

$\begin{array}{ccccccc}1 & 2 & 3 & 4 & 5 & 6 & 7 \\ \text { unfavorable } & & & & & & \text { favorable }\end{array}$

5. What do people who are important to you think about whether you should take an HIV test?

$\begin{array}{ccccccc}1 & 2 & 3 & 4 & 5 & 6 & 7 \\ \begin{array}{c}\text { Think I } \\ \text { definitely do } \\ \text { not need to }\end{array} & & & & & & \end{array}$

6. What do your friends think about whether you should take an HIV test?

Think I definitely do

not need to $\begin{array}{llllll}2 & 3 & 4 & 5 & 6 & 7\end{array}$

Think I

definitely

need to

7. What does your dating or sexual partner think about whether you should take an HIV test?

\section{Think I}

definitely do

not need to $\begin{array}{llllll}2 & 3 & 4 & 5 & 6 & 7\end{array}$

Think I

definitely

need to 


\section{Questionnaire (cont'd)}

8. What does (do) your parent(s) think about whether you should take an HIV test?

$\begin{array}{cccccccc}1 & 2 & 3 & 4 & 5 & 6 & 7 \\ \begin{array}{c}\text { Think I } \\ \text { definitely do } \\ \text { not need to }\end{array} & & & & & & & \\ \text { Think I } \\ \text { definitely } \\ \text { need to }\end{array}$

9. Do you intend to take an HIV test in the future?

$\begin{array}{ccccccc}1 & 2 & 3 & 4 & 5 & 6 & 7 \\ \begin{array}{c}\text { Definitely } \\ \text { No }\end{array} & & & & & & \\ \text { Definitely } \\ \text { Yes }\end{array}$

10. If an important person advises you to take an HIV test, will you be tested?

$\begin{array}{ccccccc}1 & 2 & 3 & 4 & 5 & 6 & 7 \\ \begin{array}{c}\text { Definitely } \\ \text { No }\end{array} & & & & & & \text { Definitely } \\ \text { Yes }\end{array}$

11. Taking an HIV test to make sure of one's health status is:

$\begin{array}{ccccccc}1 & 2 & 3 & 4 & 5 & 6 & \begin{array}{c}7 \\ \text { Definitely } \\ \text { Bad }\end{array} \\ & & & & & & \begin{array}{c}\text { Good } \\ \text { Gooditely }\end{array}\end{array}$

12. Taking an HIV test to establish or secure one's relationships with dating or sexual partners is:

$\begin{array}{ccccccc}1 & 2 & 3 & 4 & 5 & 6 & \begin{array}{c}7 \\ \text { Definitely } \\ \text { Bad }\end{array} \\ & & & & & & \\ \text { Good }\end{array}$

13. Taking an HIV test to guide one's future heath is:

$\begin{array}{ccccccc}1 & 2 & 3 & 4 & 5 & 6 & \begin{array}{c}7 \\ \text { Definitely } \\ \text { Bad }\end{array} \\ & & & & & & \begin{array}{c}\text { Definitely } \\ \text { Good }\end{array}\end{array}$

14. In general, how likely is it that you would do something your friends thought you should do?

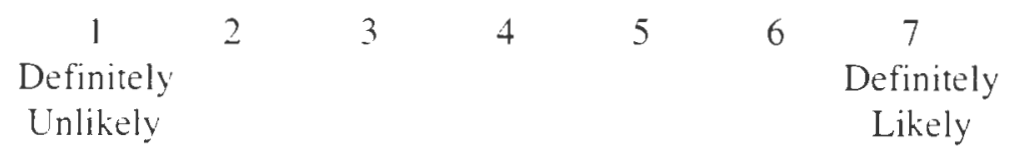


Questionnaire (cont'd)

15. In general, how likely is it that you would do something your dating or sexual partner thought you should do?

$\begin{array}{ccccccc}1 & 2 & 3 & 4 & 5 & 6 & 7 \\ \begin{array}{c}\text { Definitely } \\ \text { Unlikely }\end{array} & & & & & & \\ \text { Definitely } \\ \text { Likely }\end{array}$

16. In general. how likely is it that you would do something your parent(s) thought you should do?

$\begin{array}{ccccccc}1 & 2 & 3 & 4 & 5 & 6 & 7 \\ \begin{array}{c}\text { Definitely } \\ \text { Unlikely }\end{array} & & & & & & \text { Definitely } \\ \text { Likely }\end{array}$

17. HIV testing requires a sample of your body fluid. Which would you prefer to be taken as a fluid sample?

$$
\text { ) blood }
$$

18. If there is a choice of the location where your fluid sample is taken, which location would you prefer?

$$
\begin{array}{ll}
(\text { ) clinic or hospital } \\
(\text { ) home }
\end{array}
$$

19. In most HIV-testing facilities, counseling is provided before and after an HIV test.

In general, would you prefer to have a counseling?

$\begin{array}{lll}\text { Before testing } & \text { After testing } \\ (\text { ) Yes } & (1) \text { Yes } \\ \text { () No } & (1) \text { No }\end{array}$

20. If you received an HIV-negative test result (meaning you do not have HIV), would you prefer to have counseling?

$$
\begin{aligned}
& \text { ) Yes } \\
& \text { No }
\end{aligned}
$$

21. If you received an HIV-positive test result (meaning you have HIV), would you prefer to have counseling?

$$
\begin{aligned}
& \text { ( ) Yes } \\
& \text { ( ) No }
\end{aligned}
$$

22. How would you prefer to receive the HIV test results?

() face-to-face with a doctor or a clinic staff member

( ) by telephone 
Questionnaire (cont'd)

23. If an HIV testing procedure incorporated all the conditions you prefer, how likely is it that you would take an HIV test in the future?

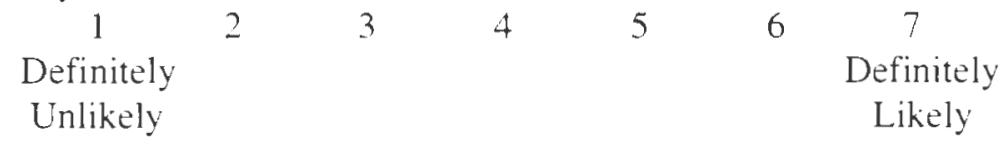

\section{4. ((optional))}

In question 17 through 22 of this section, why did you choose the options you did? What is (are) the reason(s) in your response in question 23 ?

\section{$<$ Information about yourself $>$}

25. Age:

26. Sex: (male or female)

27. Ethnic/racial group:

- White

African-American

Hispanic

Asian/Pacific Islander

Other

28. Current relationship status:

_ legally married

_ living together as married

_ single with partner but not cohabiting

_ single without partner

29. Sexual orientation: _ heterosexual

$$
\begin{aligned}
& \text { _ } \begin{array}{l}
\text { homosexual } \\
\text { bisexual } \\
\text { other }
\end{array} \\
& -\quad \text { L }
\end{aligned}
$$

30. Have you taken an HIV antibody test before?

$$
\begin{aligned}
& \text { Yes } \\
& \text { No No } \\
& \ldots \text { do not know }
\end{aligned}
$$


Questionnaire (cont'd)

31. How concerned are you with HIV or AIDS as a social problem?

not at all

_ slightly concerned

__ quite concerned

_ extremely concerned

32. How much do you think that you are at risk for HIV?

- not at all

_ slightly at risk

_ quite at risk

_ extremely at risk

33. How much do you think that people your age are generally at risk for HIV?

not at all

_ slightly at risk

_ quite at risk

- extremely at risk 